\title{
Global leadership development
}

\author{
What's in it for me?
}

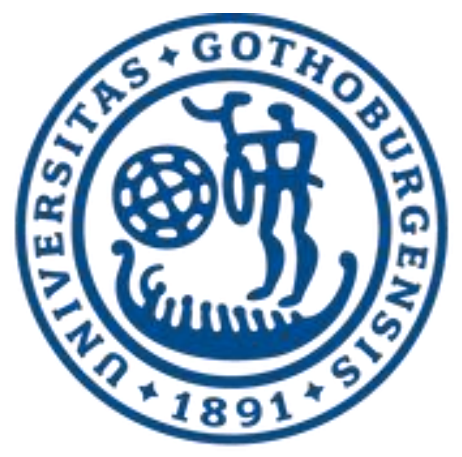

\section{UNIVERSITY OF GOTHENBURG}

Master of Strategic Human Resource Management and Labour Relations 30 higher education points

Author: Jonathan Gradén

Supervisor: Harald Dolles

Examiner: Maria Tullberg

Faculty of sociology and work science

Spring semester 2014 


\section{Abstract}

Problem - An arguably new breed of leaders, the so-called global leader, has become prevalent among several multi-national corporations. Lacking a precise definition, previous research shows their impact on international companies overall performance to be severe. Though a number of different - and disparate - methods exist for their development has been suggested, it is unclear what motivates their participation in development programs.

Purpose - This thesis approaches the issue of global leader development from the perspectives of both the individual and the company, determining what development tools are available to the company and the reasons global leaders have to attend them.

Design - Using a case study design, employees at a Swedish global engineering group was in focus. Five interviews provided information regarding human resource systems and development tools, whereas 10 individuals at the company headquarters were interviewed regarding issues relating to global leader development. The results were analysed via the expectancy theory framework in order to determine what motivates global leader participation in development programs.

Findings - Opportunities of knowledge development, individual development, networking opportunities, social interaction were mentioned as reasons for development program attendance. The international aspect however, was rarely mentioned in a positive light. None of the interviewees expected the development programs to advance their careers directly.

Key words - Global leader, expectancy theory, development programs, motivation

Number of words - 22975 


\section{Acknowledgements}

One is so rarely given the chance to publically acknowledge the contributions of the important people in one's life. This being a chance to do just that, I intend to do so to the fullest extent of my will. Though academic prudence sometimes limits the style by which one can formulate oneself in text, the importance of such rules in relation to this one section of my thesis is overruled. For those that consider this section inappropriate, feel free to move along, in this section I will thank whoever I see fit.

And the king of Norway.

To begin with I would like to thank my supervisor for his patience and for the ideas given to me during our conversations. I would also like to thank Erika Thielfoldt, who wrote her master thesis in the same program a year before me, and whose thesis served as an inspiration to me.

I would like to thank everyone at Circfor for their participation in this study. Without you, this thesis would not have been possible. Relatedly, thanks to the receptionists of the company for being plain wonderful to me.

Most importantly, I would like to thank my dear mother, father and siblings for not only supporting me in innumerable ways, but also keeping my spirits up during the writing of this thesis. I love you.

To all my friends knowing I was writing this thesis, be you intellectuals, whackos, clowns, partners in crime, dorks, badasses, Jedis, Gandalf, or plain nice people - a very sincere thank you. You may be the ones raising your hands to your cheek when smiling, forgetting to wall off, maybe you biked through Russia, maybe I gave you a coffee mug, maybe you are, and shall always be, my friend. Perhaps you discussed politics with me cynically over a beer, or told me that Mal'Ganis was alive again, maybe you found the bastard, perhaps your brother gave me somewhere to live, or I stole your bag on film, maybe we used to date, you might have given me coffee, perhaps we met in Heidelberg, Tilburg or Bochum. Some of you are away far, some of you are near, but to me, you will always be very dear.

A special thank you goes to Keno Don Hugo Rosa for teaching me morals since I was about ten years old. Relatedly, a big thank you to SF Debris (alias Chuck) for being instrumental to make me actually perform my work during this entire semester. You really made me get over that Threshold.

In short order, I am thankful to all of you and for the possibility to tell you what you mean to me by including you in this section. Though I am somewhat proud of this thesis, it gives me more joy to know that you are all in my life.

Thank you. 


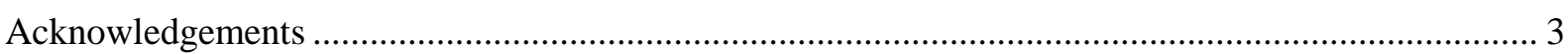

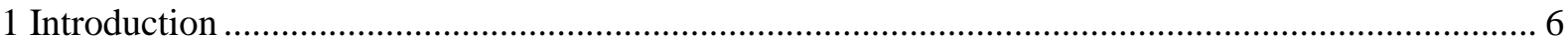

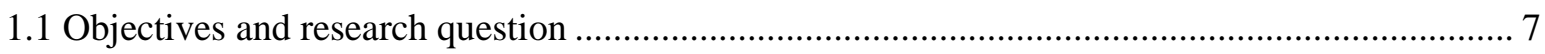

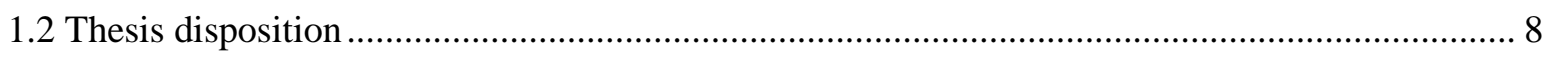

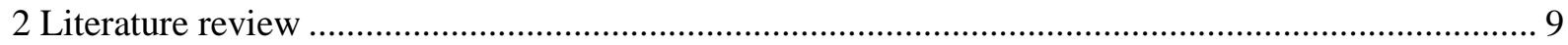

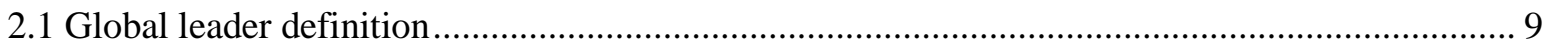

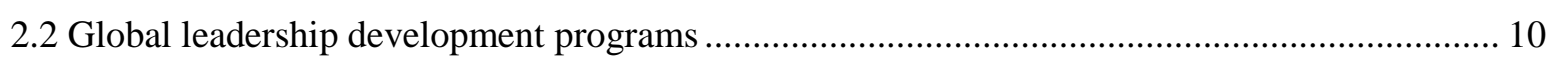

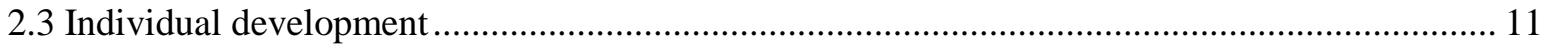

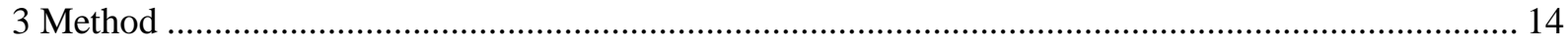

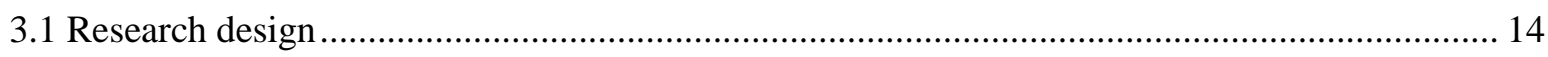

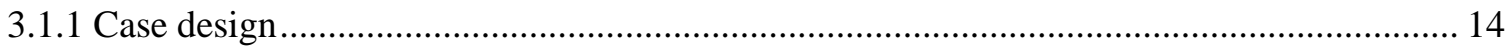

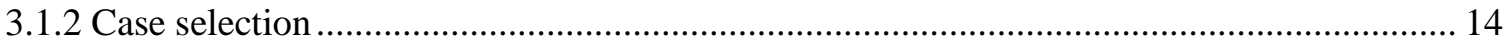

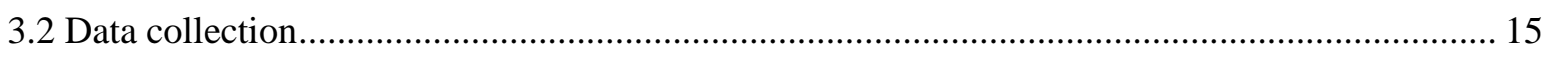

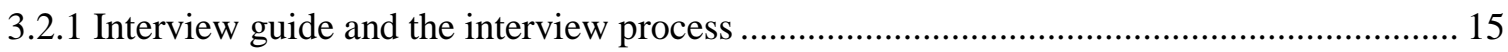

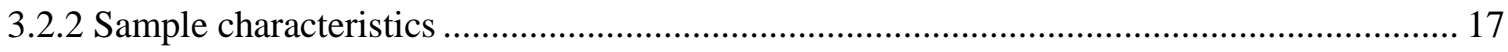

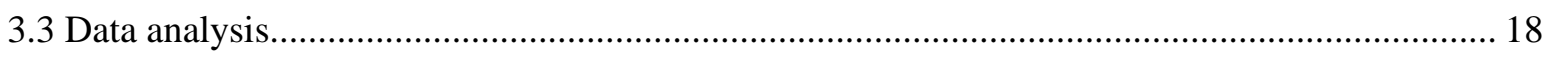

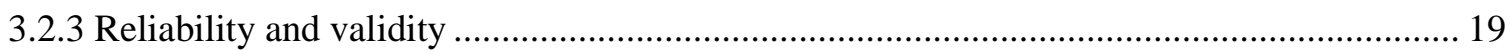

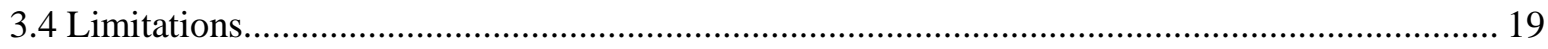

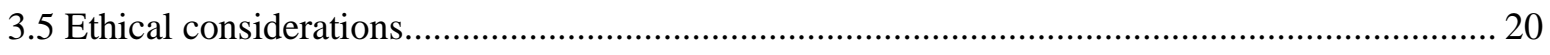

4 Findings

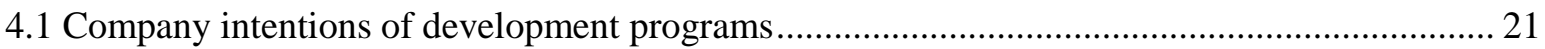

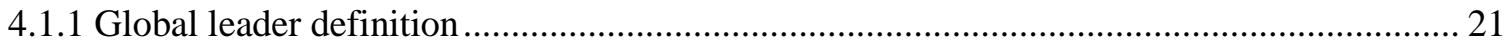

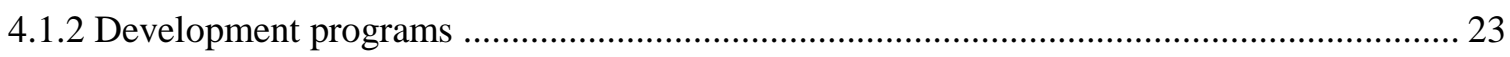

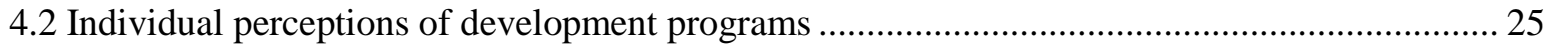

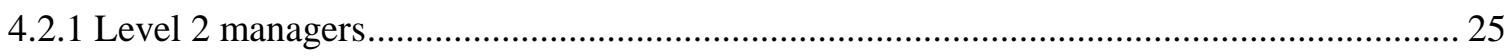

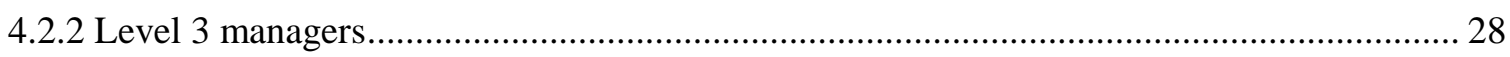

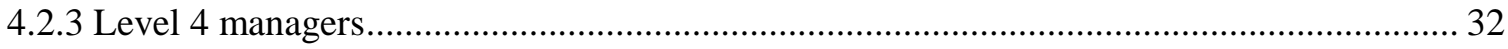

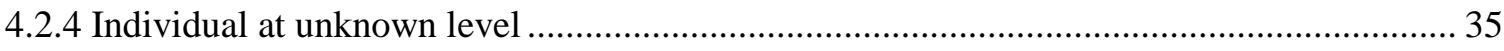

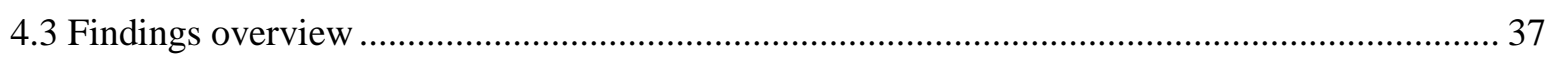

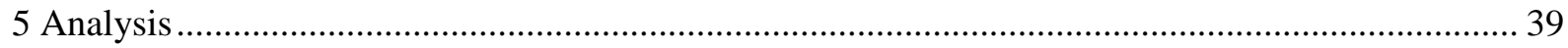

5.1 Interviewee motivations and the expectancy theory framework ............................................... 39

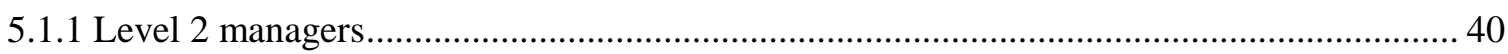

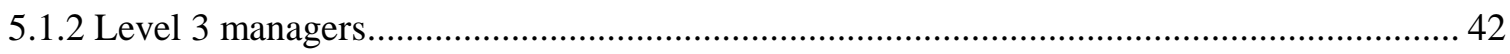

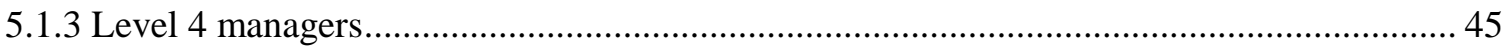

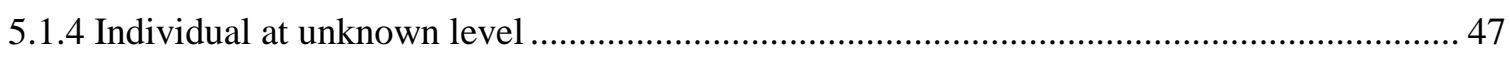

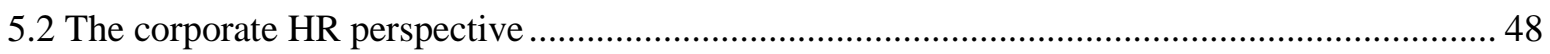

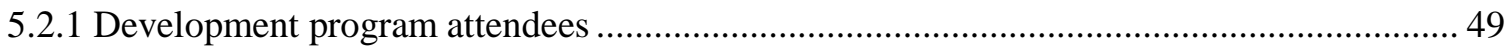

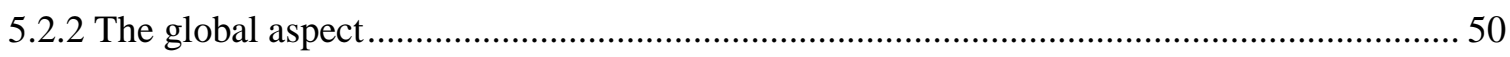




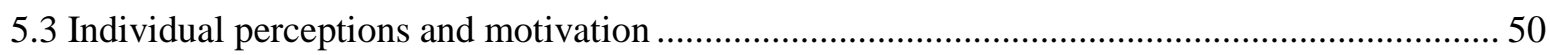

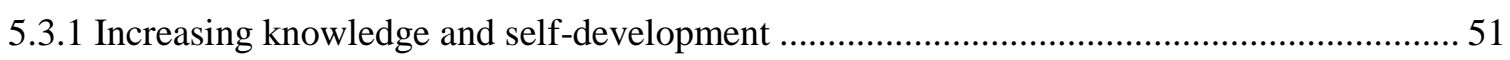

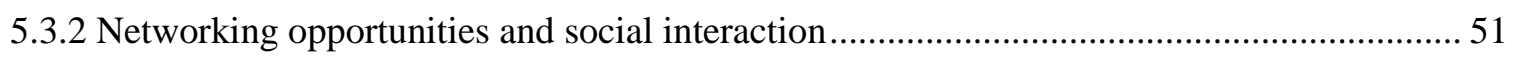

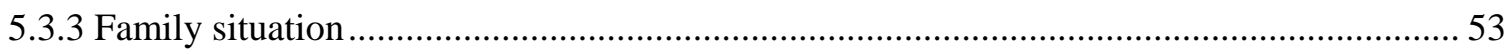

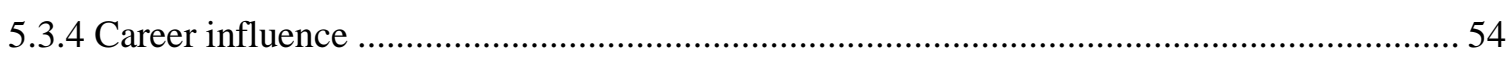

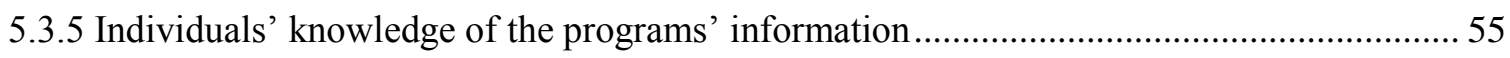

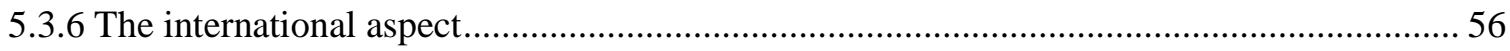

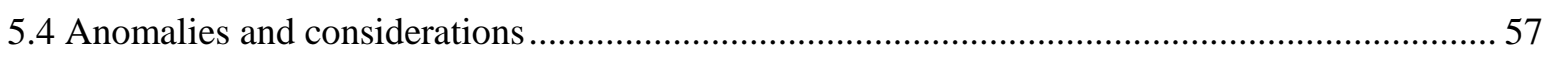

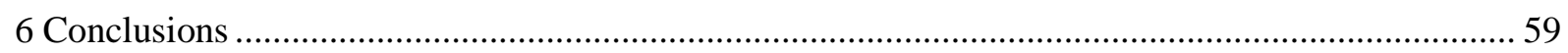

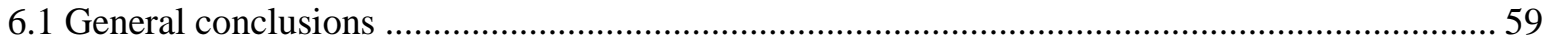

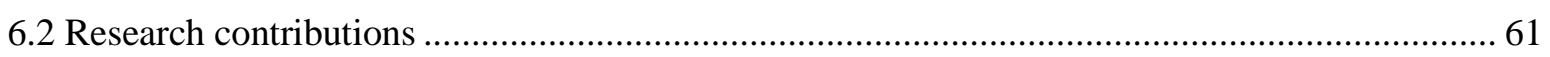

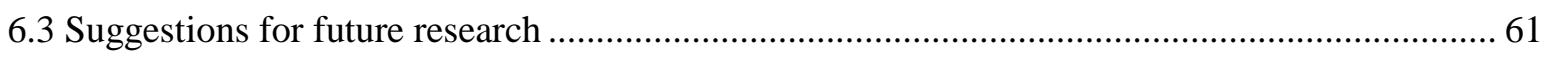

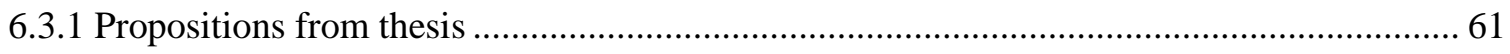

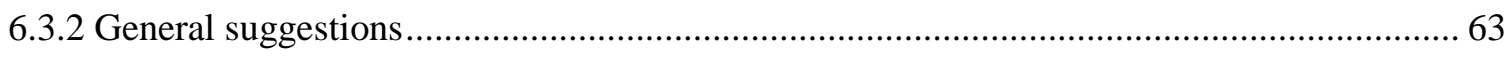

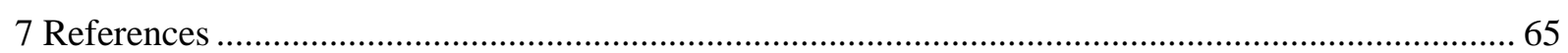

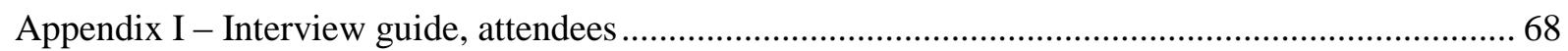

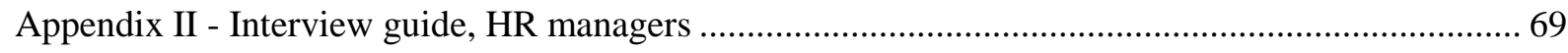




\section{Introduction}

The world of today is a rather globalized one, a fact mirrored in the nature of modern business. Many companies nowadays are not restricted to merely one country, but are present in a number of countries. These multi-national corporations (or MNCs) thus face the challenge of managing their enterprises not only across national borders, but also across cultural ones. This global and dynamic environment is something that MNCs have to manage effectively in order to achieve sustainable growth and they thus need employees and managers capable of handling issues of a global nature. As a consequence, an arguably new breed of leaders has emerged: so called global leaders. The exact definition of this term is not set in stone, partly because of different definitions proposed in different research papers (Caligiuri 2006; Gregerson et al 1998; Caligiuri \& Tarique 2009), but also because global leaders may very well have different areas of responsibility, making one sharp definition unpractical.

Irrespective of the definition of the term, the fact that they can be of significant value to the firms employing them does not seem to be in dispute (Collings \& Mellahi 2009). Ready \& Conger (2007) surveyed a total of 40 global companies, virtually all of which stated that they were unable to fill important global strategic positions of their firms and suffering financially because of it. Gregerson (1998) found that more than $80 \%$ of their surveyed companies did not have sufficient global leaders in their organizations - and $67 \%$ of these stated that their global leaders did not have the appropriate skills for their position! That a lack of global leaders can cause financial or organizational troubles has been documented as well (Bartlett \& Ghoshal 2003; McKenzie Quarterly 2008; Morrison 2000; Oddou et al 2000). Given the fact that these global leaders seem to be of tremendous importance, it may not be surprising that the field has received attention - yet much research on the subject still maintains that there is a massive lack of empirics in just about every field of research relating to global leaders (Jokinen 2005; Morrison 2000; Suutari 2002).

The fact that the definition of global leaders is rather unclear in combination with the possible different functions of global leaders leads to a rather interesting situation regarding their development. Though there has been a great deal of research suggesting how to develop these individuals and what factors to consider (see for instance Morrison 2000 or Jokinen 2005), this particular area of research remains rather unclear and anything but uniform. Given the 
fact that global leaders appear to be of fundamental importance to companies and the fact that the competition between companies for these individuals, developing as many of these individuals as possible appears to be of paramount importance. One way to train global leaders is international experience, suggested by among others Gregerson et al 1998. Another method is formal educations and development programs, discussed by among others McDonnel et al (2010). Though the issue of what motivates individuals to take part in international assignments has been discussed at length (Oddou et al 2000; Harzing \& Pinnington 2011; Briscoe, Schuler \& Tarique 2012), motivating global leaders to partake in development programs has received little attention.

Using a case study approach to study a number of global leaders in a Swedish polymer technology company, this thesis aims to investigate how global leader development programs are designed and aimed in order to benefit global leader development. Furthermore, with the nature of the development programs being described, this thesis aims to explain what motivates global leader participation in developmental programs, interpreting the results via Vroom's expectancy theory. The ultimate result of this thesis could help human resource practitioners identify the most important aspects for motivating global leaders, and hopefully thus determine what issues should be at the centre of global leadership development.

\subsection{Objectives and research question}

Using a case study investigating a Swedish multi-national corporation, this thesis aims at unveiling the reasons for global leader attendance in global leader development programs and the nature of the available global leader development programs. In order to understand the global leaders' willingness to participate in such programs, information from the human resource (or HR) side of the company as well as attendees in such programs will be relevant. As such, two research questions emerge:

Research question 1: What is the nature of the development programs available for promoting and developing the skills and talents of the workforce sought after for global leadership positions?

This question aims to discover how companies develop the workforce's skills. What are the intended outcomes of these programs, and what is offered to the individuals? 
Research question 2: What encourages global leaders to participate in development programs in multi-national corporations?

The existence of development programs is likely to be of little use if their employees are not motivated to attend them. An unmotivated workforce is probably unlikely to benefit as much from developmental programs as a properly motivated one.

\subsection{Thesis disposition}

\section{Chapter 2 - Literature review}

This chapter conducts a literature review of relevant earlier research in the field of global leader development and highlights current definitions. It also presents the theoretical framework used in the thesis.

\section{Chapter 3-Method}

This chapter describes the method by which the case was chosen, analysed and presented. Included is also a short overview of the individuals in the case, as well as the methodological limitations of the thesis.

\section{Chapter 4 - Empirical findings}

This chapter presents the findings of the interviews and the secondary material. The motivation of the employees and the allure of the development programs are presented here.

\section{Chapter 5 - Analysis}

This section contains an analysis of the findings presented in chapter 4 . The theoretical framework presented in the end of chapter 2 serves as the lens by which the results are interpreted.

\section{Chapter 6-Conclusions}

This section provides a summary and presentation of the most significant results of the thesis. It also contains limitations of the findings, as well as suggestions for further research. 


\section{Literature review}

This section is divided into three sections. The first addresses the definition of a global leader, characterised by being rather fragmented. The second section is the body of literature referring to how current global leaders are developed. This area is hardly more concrete or uniform than the last, yet a number of common findings in this field are very much worth noting. The third section refers to motivation with regards to global leadership development. The fourth and final section aims at finding a relevant motivational theory to be used for analysing the findings.

\subsection{Global leader definition}

Though the term "global leader" has been used in a wide array of papers (Caligiuri 2006; Caligiuri \& Tarique 2009, Gregerson et al 1998; Morrison 2000; Ready \& Conger 2007), there is no universal definition of the term. Furthermore, the term includes individuals of different trades, talents, responsibilities and hierarchical positions, furthering the fragmentation of its definition. The consequences of this vagueness have, rather unsurprisingly, led to some unexpected results. For instance, in her review of global leadership competencies, Jokinen (2005) found that one research paper regarding a prominent tool for global leadership development (international assignments) has been done on expatriates, yet the findings have been assumed to be accurate for global leaders as well. Another view was presented by Bartlett \& Ghoshal (1992), who suggest that global leaders are not single individuals, but a concept made up by a network of individuals sharing their experience.

Nevertheless, the sheer number of research papers so far which have operationalized and utilized different (though reminiscent) definitions of global leaders suggest that individuals fulfilling certain criteria may be defined as global leaders. Jokinen (2005) states that de Vries \& Florent-Treacy (2002) refer to global leaders as any one position merging the roles of manager and leader, while Gregerson et al (1998) focus on character traits and certain business qualities to refer to successful global leaders. Another definition was provided by Caligiuri \& Tarique (2009), who define global leaders as "high level professionals such as executives, vice presidents, directors, and managers who are in jobs with some global leadership activities such as global integration responsibilities". This definition was recommended by among others Harzing \& Pinnington (2011), citing it to be "a helpfully 
succinct definition" (Harzing \& Pinnington 2011, p 381). The fact remains however, that this is a broad definition, leading to the possibility of including a rather broad population of the case company. The issue of whom to interview from the case company is addressed under section 3.2.1.

\subsection{Global leadership development programs}

To begin with, much research suggests that intercultural training and the development of a global mind-set is of significance when developing global leaders (Caligiuri \& Tarique 2009; Gregerson 1998; Oddou et al 2000; Townsend \& Cairns 2003). The common reasoning is that in order for global leaders to be able to handle situations of a cross-cultural nature, experience in those areas is extremely beneficial. The recommendation of cultural training is not limited to exposure to foreign cultures, but coupled with other training tools. Gregerson et al (1998) for instance suggest that global leaders need to be of keen inquisitiveness, have a certain character and possess business and organizational savvy to be successful. The idea of traits as an important concept is wide-spread, shared by Rabotin (2008) among others. Caligiuri (2006) takes a similar view, but suggests that personal characteristics should be matched by appropriate development programs.

Cacioppe (1998) discusses how to properly design such development programs, mentioning factors such as a global focus, personal development and improved business and leadership skills to be of paramount importance for properly developing global leaders. Apart from highlighting what factors should be emphasized upon when discussing the content of development programs, this paper also suggests details in terms of methods when planning the program's method and layout, suggesting activities such as exercises, role plays and business game simulations to be beneficial.

In a somewhat similar vein, Leskiw \& Singh (2007) highlight the fact that successful development programs must conduct a proper needs assessment, find a suitable audience, create infrastructure to support the learning system and more. McDonnell et al (2010) found that a number of large companies may have instruments and plans in place for the development of their talents and global leaders, but fail to adopt a succession planning system, implying that the developed individuals will have little chance to make us of the skills they recently acquired. Relatedly, Ready \& Conger (2007) investigate why the development of global leadership talents fail, citing top-level control wishes and a product view of 
leadership development as top reasons for failure, implying that the design of the programs should not be overly top-designed.

Though the findings above suggest how to properly design development programs and what can cause them to fail, the reasons for global leaders to participate in these programs has not been made clear. The next section aims to shed light on this issue.

\subsection{Individual development}

This section investigates and relates to the influence that the individual has on his or her own development. The amount of research done on this issue is far from as extensive as the previous two fields presented however. Though the development of global leaders has received extensive attention as stated above, this question appears to have received little attention. There appears not to be any previous research asking the question of what encourages global leaders to partake in global leader development programs, which is the focus of this thesis. A number of papers have addressed issues bordering this question however. Gregerson et al (1998) suggested that inquisitiveness fuels motivation needed to partake in cultural exchange and develop a truly global mind-set. One of the most important aspects for global leader development is the development of such a mind-set (Schuler, Jackson \& Tarique 2012; Pless et al 2011), though sadly Gregerson et al's findings apply to general populations rather than to an individual basis. Colquitt et al (2000) found that individual characteristics, for instance job involvement, and situational characteristics were relevant to job motivation.

Though these papers offer little insight on the question stated by this thesis, they offer increased evidence for the relevance of motivation on part of the global leader regarding their development. However, the impact of motivation on job performance is an aspect which has been delved into more extensively within psychology, and is outside the scope of this thesis. Hence, it is important to investigate what factors motivate potential and current global leaders to take part in global leadership development programs. As such, a motivational-based theory is necessary. The expectancy theory (presented first by Vroom 1964) provides an excellent framework for allowing the analysis not only of how individuals decide whether to increase their performance, but also how they reach desirable goals by use of a step-by-step decision making process. The theory has the advantage over other motivational theories of investigating individuals and taking their personal perceptions into consideration, and not 
assuming individuals to behave in the same way. The expectancy theory uses a number of concepts, all explained below.

First-order outcomes are the outcomes individuals expect they can reach via increased effort. An individual may assume successful participation in a development program to lead to, for instance, increased work knowledge on his part. The increased knowledge is the desired result of the effort put into attending the program, and is referred to as a first-order outcome. For example, a global leader could desire increased networking opportunities, and attends a program and struggles to complete it in order to gain increased knowledge of his work field (his first-order outcome). Once successful participation in the program is confirmed, this leads to the second-order outcomes - the ultimate goal and motivation for the employee. These outcomes could be increased salary, recognition from one's boss etcetera, but in this example it will be increased knowledge of the job field. Once goals are set up, his calculations of getting there enter the equation. (Campbell \& Pritchard, 1976)

Expectancy refers to whether or not the first-level outcomes can be reached. Does our global leader think he can finish the program if he attends it? If the answer is no, there is little reason for the employee to attend. This assessment is affected by the individual's self-efficacy, the difficulty of the goal, and the perceived control that the individual has over his own performance. Instrumentality refers to the belief that achieved first-level outcomes will lead to the second-level outcomes. Once the program has been completed, will it lead to the desired outcomes? Will attending the program actually lead to the increased knowledge he so desired? Again, if he believes attending the program will NOT earn him increased knowledge (his second-level outcome); he will not be motivated to attend. Also, the degree to which he desires the outcome, known as valence, becomes relevant. In order for the individual to be motivated to partake in the program, the second-order outcome has to be desirable. If our global leader indeed wanted this additional knowledge, then he would be motivated to perform. However, if this knowledge were not attractive (due to, for instance, an unwilling family), this outcome would not motivate him to attend the program. (Campbell \& Pritchard, 1976)

This theory can be used to determine what motivates potential and current global leaders to take part in development programs. The fact that there are individuals attending these programs to begin with suggests that individuals realise that they can indeed bring benefits, 
but it is unknown what factors motivate global leaders to attend. It should be noted however, that the goal of this thesis as such is not verifying the validity of the expectancy theory, rather using it as a framework for interpreting the empirical findings. 


\section{Method}

This section lays out the nature of the thesis and what research methodology was employed in order to obtain relevant information. It also explains how data was structured and analysed.

\subsection{Research design}

This section explains what research methods were used and why this particular case was relevant as a study object.

\subsubsection{Case design}

Since the aim of this thesis is discovering how MNCs encourage the further training of their global leaders, it would benefit from a qualitative design. Seeing as how one singular company is in focus, a case study would be most prudent, having the ability to investigate and reveal subtle nuances and find information about complex and little-known phenomena. Though a quantitative study is possible, it lacks the analytical sharpness to delve into personal stories and the reasons behind personal motivation and company thought processes. It should be noted that while the company, Circfor, is viewed as a case on its own, the interviewees individually are viewed as embedded cases in the Circfor case. As such they can be analysed in their own right, yet the policies made on part of the Circfor HR department may apply for all of them. (Gummesson, 2007)

Though qualitative research studies can make few claims to generalizability, they can be rather beneficial for theory generation. (Gummesson, 2007) It is the aspiration of this thesis to in the analysis section find patterns of relevant factors regarding both personal motivation and company policies to be able to make certain assertions and propositions, which could then serve as blueprints for further research.

\subsubsection{Case selection}

In order for a company to be a proper object for study in this research, two criteria have to be met. First, the company will have to have international reach. By its very definition (there is yet to surface a definition of a global leader which does not require a global aspect), global leaders have to work in a company with international reach. Furthermore, even if that were somehow not to be the case, a global company is far more likely to provide global leaders than a purely domestic one. Second, the company would have to have a number of individuals to whom one can refer as global leaders. As such, the bigger the company, the more likely it would appear that an elite cadre of individuals would exist, and thus be eligible for the title of 
global leader. Furthermore, a company with a clear Human Resource and Talent Management System would be more likely to have an internal structure which could more easily identify such an elite echelon.

An examination of several well-known enterprises revealed a Swedish global engineering group focusing on polymer technology, which after probing by pilot interviews appeared as an ideal case. To protect the anonymity of the company and its employees, it was designated the pseudonym "Circfor". The company employs roughly 20000 employees in more than 15 countries, with its headquarters in southern Sweden. The company utilizes a multi-layered HR system, thus being able to refer to its employees in different levels of advancement. For example, level 1 denotes the chief executive officer; level 2 refers to Business Area Presidents, level 3 managers report to business area managers, etcetera. During the probing interviews it was indicated that though the company does not strictly use the term "global leader" in its day-to-day operation, this is partly because of the inherent structure and nature of the company. Due to its international structure, any manager or employee above level 5 will have international responsibilities.

\subsection{Data collection}

This section describes what kind of data was collected and what methods were used in collecting them. A table offering an overview of the interviewees is also presented.

\subsubsection{Interview guide and the interview process}

The interviews were carried out by help of two interview guides geared towards discovering the motivational factors for individuals to participate in the global leader development programs and developmental program content respectively. The motivational interview guide related to factors described in the expectancy-theory framework, as explained in Campbell \& Pritchard (1976). Both interview guides were designed as semi-structured questionnaires, in order to provide desired flexibility. A semi-structured interview guide is preferable to an unstructured one, because the most critical questions stay the same during the interviews while at the same time being open enough to allow the interviewee to deviate from the plan and add additional information. An unstructured interview risks the interviewees focusing on very different factors, making comparison between companies complicated. (Hakim 2000)

The interview process commenced, as recommended Hakim (2000), by a number of pilot interviews in order to improve the quality of the questionnaire before using them in their final 
capacity. During the course of the pilot interviews, it became clear that global leaders have a certain degree of leeway in deciding the direction of their careers. The focus of this thesis was initially aimed at determining the effect of increased independence on part of the global leaders, though its direction was altered when pilot interviews revealed the rather hypothetical nature of such a development. Relatedly, it became clear that while individual coaching and similar procedures were available for global leader development, the mainstay of the interviewees had attended company development programs, making the issue of development motivation extensively simpler to investigate if limited to such programs. Additionally, pilot interviews also revealed the difficulty of determining the effect of organizational culture on global leader development, a factor which was therefore removed from the final questionnaire. Increased emphasis was thus put on individual motivation.

The interviews were conducted with merely the interviewer and the interviewees present, although the location of the interviews varied. Of the motivational interviewees, each participant was asked to explain his or her decision making process regarding whether or not to participate in a global leadership development program. Furthermore, interviewees were asked to delve and explain further why these decisions were made. The interviewees in the more informational interviewees were asked about the nature and content of different development programs, and the company structure itself. All interviews lasted between 20 and 60 minutes, each interview being preceded and followed by a short informal discussion. The content of the preceding discussion included ethical considerations, and are addressed in section 3.5.

Each interview was recorded by use of a smartphone application and coded using Atlas.ti 7. The purpose of the recording device was twofold: first, to remove the necessity of intensive writing by the interviewer during the interview, and secondly to allow the interviewer to keep the discussion for later transcription. The purpose of transcribing the interviews was to make its coding in the Atlas.ti-program easier, and to heighten validity by allowing faster access to its content. Three interviews were conducted in English, but translated and transcribed into Swedish to facilitate its comparison with the other fourteen interviews, which were conducted in Swedish. As such, all and any quotes were translated and transcribed from Swedish to English, unless indicated otherwise. 


\subsubsection{Sample characteristics}

Determining what motivates individual motivation for taking part in development programs could be done by collecting information via questionnaires or interviews alike, though the latter option is superior in depth and flexibility, and was thus chosen. The primary data collection was conducted by means of interviews with ten individuals corresponding to the definition of a global leader. All interviewees belong to level 4 or above, with one being somewhat unsure of his level.

All interviewees asked about motivation had either previously taken part in global leadership development programs, or were currently doing so. It should be noted that individuals of different levels were present, denoting a difference in the number of programs attended, as well as their hierarchical position in the company. The table below provides an overview of how many individuals belonged to what levels. In the findings and analysis sections, none of the interviewees are referred to their real names, but are given a pseudonym. These pseudonyms are in no way connected to the person's real name, yet correspond to the gender of the interviewee. As will become clear in the "Findings"-section, the Circfor hierarchical structure is not absolute, meaning that a person is not always certain of his own level. As noted with Mr Franklin, he is indeed not certain of his level, likely influenced by the fact that he is new to the company. Also, the level-system is based on steps away from reporting to the chief executive officer (CEO). Since this in some cases is a matter of interpretation, some levels may vary one level down or up. Still, none of the reported levels is lower than 4 , perhaps excepting Mr Cox.

Table 1: Motivation-related interviews

\begin{tabular}{|l|l|l|l|}
\hline $\begin{array}{l}\text { Interviewee } \\
\text { Alias }\end{array}$ & Level & $\begin{array}{l}\text { Attended } \\
\text { program }\end{array}$ & Role \\
\hline Mr Sinclair & 2 & TED & Business area president \\
\hline Mr Bester & 2 & GOLD, TED & Head purchasing manager \\
\hline Mr Sheridan & 2 & TED, external & Business area president \\
\hline Mr Allan & 3 & GOLD & M\&A controller \\
\hline Mrs Winters & 3 & None & Business area HR vice president \\
\hline Mr Cole & 3 & TED & Head group finance manager \\
\hline Mr Garibaldi & 4 & External program & Group training and development manager \\
\hline Mrs Alexander & 4 & None & Group level financial controller \\
\hline Mrs Ivanova & 4 & NODE & HQ purchasing manager \\
\hline Mr Franklin & $?$ & None & Supply chain management manager \\
\hline
\end{tabular}


Working with HR-questions in the company headquarters, the interviewees below were asked questions regarding Circfor's development programs. As such, they were not asked questions about their own motivation for partaking in development programs.

Table 2: HR manager interviewees

\begin{tabular}{|l|l|l|}
\hline $\begin{array}{l}\text { Interviewee } \\
\text { Alias }\end{array}$ & Level & Role \\
\hline Mr Kelso & 2 & $\begin{array}{l}\text { Senior Vice President of Human } \\
\text { Resources }\end{array}$ \\
\hline Mr Sullivan & $3-4$ & Talent Management Director \\
\hline Mr Cox & $3-5$ & Corporate HR officer \\
\hline Mrs Reed & $2-3$ & Business area HR vice president \\
\hline
\end{tabular}

A critical reflection of the selection of the interviewees would be beneficial. The five informational interviews regarding the HR layout of the company were selected because of their positions. A total of seven individuals were requested to partake in these interviews, two citing practical inability to attend and thus were not included. The ten motivational interviewees were found by assistance from the head HR managers' assistant, providing a list of individuals at appropriate levels. One additional interviewee did not attend the interviews, citing scheduling reasons. Though the individual appeared enthusiastic about the interview, the possibility remains that this was not the true reason.

A quick overview of the interviewees reveals that three of the ten motivational interviewees were women, and one of the four HR-related ones. The literature relating to global leadership development has had little focus on gender differences, and severe differences are thus not expected to appear in this thesis. However, given the fact that psychological issues are stated by some as having an effect regarding will and efficiency of development, one should not disregard the possibility that gender issues could be related. This topic is outside the scope of this thesis, however.

\subsection{Data analysis}

The ten interviews relating to the individual motivation were transcribed and converted to .rtfformat, to facilitate their use by Atlas.ti 7. To expedite the extraction of information, a number of codes were used. The purpose is the increased versatility provided in comparing similar concepts across different interviewees. Rather than presenting a complete list of all codes used (73 in total), the major codes will be presented. The five informational interviews had 
their own set of codes but were analysed in the same heuristic unit of the program, meaning that the codes used were part of the 73 codes mentioned above.

The major codes were rather different though, the major ones including target groups of the programs, the definition of global leaders, program length and program outcomes. Since the motivational factors of the development program participants could not be known beforehand, several codes were developed as sub-codes. For instance, rather than limiting the codes to "extrinsic program motivation", the code "network and contacts" was created, though subordered to the previously mentioned code. Similar considerations apply to the section regarding development program content.

\subsubsection{Reliability and validity}

With primary data provided by of two different forms of interviews, additional information was acquired by documents related to the Circfor organizational structure as well as documents relating to the content and aim of the different developmental programs. The reason for the inclusion of such documents was partly to cover areas not described fully in the informational interviews, but mainly to allow data triangulation and thus increase reliability. As a concept, reliability refers to the certainty that one can conduct the same test several times and receive similar results. In the case of these interviews, following the same interview guide with each employee increased the likelihood of getting answers similar to one another (in topic). Furthermore, though the motivations on part of individuals are not easily confirmed by secondary sources, the use of different documents can confirm some information provided in interviews, an idea called data triangulation (Gummesson 2007). If the content of the documents correspond to the data provided in the interview, the reliability of the information is thus incrementally increased. This is especially applicable in the informational interviews. Validity, the degree to which one discusses the issue actually in focus, is somewhat different. In terms of internal validity, it is important to confirm the contents of the information provided by the interviews. This was done by repeated listening to the recorded conversations to minimize the risk of misunderstanding.

\subsection{Limitations}

Being in nature a rather exploratory research, this thesis aims to discover how global leaders are motivated to partake in different development programs by investigating a small number of employees in a single company. One drawback of this study is thus its lack of external validity. Though qualitative research by its very nature all but sidesteps such claims, it does 
mean that the findings of this study essentially should be replicated in order to validate its findings. Furthermore, since the interviews were done on a one-time basis, the issue of changes over time cannot be addressed. From a dynamic point of view, the interests of the interviewees and their motivation for partaking in different programs may change over time, which this study is essentially incapable of compensating for.

\subsection{Ethical considerations}

The issue of company anonymity and participant anonymity has been addressed in previous sections. With regards to ethical consideration during the interviews, a number of actions were taken. Every individual was assured anonymity before the interview started. Furthermore, each individual to abort the interview at any time, and asked if there were present before the interview started. The interviewees were informed of the recording device, as it would not have been used unless accepted by the interviewee. Each employee was told of the right to correct his statement before the thesis was published, and the company was assured the right to take part of the thesis once finished. Though there are numerous sources available for ethical guidelines with regards to interviews, the one above stems from Hakim (2000). 


\section{Findings}

This chapter presents the empirical findings acquired from the primary and secondary data. The first section refers to the nature of the different development programs. It also includes a section referring to the definition of global leaders made by the company. The reason for including such a section is its parallel to the global definition used in this paper mentioned in the theory section as "high level professionals such as executives, vice presidents, directors, and managers who are in jobs with some global leadership activities such as global integration responsibilities". The second section relates to the results of the individual interviewees and their motivations for participating, the outcomes they expected to gain, whether they would have participated voluntarily, and other questions. The interviewees are divided into four groups made up of three employees based on their management levels, though each individual's interviews are described separately. As small description of what defines each management level is included as well. At the end of the chapter, an overview of the results is presented.

\subsection{Company intentions of development programs}

In order to comprehend the nature of the development programs offered by Circfor and gaining some understanding on how they view the development of global leaders, five interviews were conducted with HR professionals at the firm. First and perhaps most notably is the head of the Group HR department, Mr Kelso. Second, Mr Sullivan is the head HR manager of one of the business areas and also leads the Talent Management development at group level. Third, Mrs Reed is the head HR manager of a different Circfor business area. Fourth, Mr Cox is a subordinate of Mr Kelso and works within the corporate HR department. A fifth employee was interviewed as well, but the information provided by that interview was unfortunately not of significant relevance, and has thus been excluded from the thesis. First, the definition of the term global leader in Circfor is discussed. After that, the information regarding Circfor's development programs is presented.

\subsubsection{Global leader definition}

Strictly speaking, the term global leader is not a concept being actively used within Circfor. When presented with the terminology and definition of global leaders presented above, the respondents all concluded that the term is not in active use, yet the description essentially fits most (if not all) of the managers at level 1-4, a view to which Mr Cox gave his support. 
Though a clear boundary was not set because of the absence of the term itself, Mr Kelso explained that level 5 managers and below were more likely to have a regional or local area of responsibility, and that a task of major importance was the issue of developing these managers to higher levels, a topic to which is further elaborated in section 6.1.2.

Because of Circfor's international structure, the absolute majority of the managers at these levels have international responsibilities, contacts and tasks, requiring them to be deal with issues of an international nature. Indeed, Mrs Reed explained that the company expects her employees to be able to handle positions in other parts of the world, be it long-term or shortterm assignments. She theorized that due to Circfor's inherently international structure, the belief that one understands various cultures and has a second nature in the international field is rather wide-spread within the company, meaning it might not be very highlighted. Quoting her, “... perhaps it's in the wrist [Swedish: spine] of many of those who have worked here for a long time". Mr Sullivan in a similar statement mentioned that Circfor indeed has a global perspective, reflected in their organizational structure, a statement which Mr Cox supported, mentioning that a number of managers and employees by definition work in and via international teams, emphasizing the differences in cultures between the members in those teams.

It was also revealed that competent individuals at higher levels indeed could be given assignments abroad because of their intimate "Circfor-knowledge"; because they had a certain familiarity with the Circfor culture and could further spread and entrench the organizational culture to the location they were travelling to.

Individuals fitting the global leader definition essentially had to have a global mindset. $\mathrm{Mr}$ Kelso explained the importance of such a mindset, concluding that possessing that advantage could be beneficial, if not necessary, stating numerous examples in which the absence of such sensitivity could lead to cultural misunderstandings and breakdowns in communication. $\mathrm{He}$ emphasized that a more multicultural environment could be all but inescapable in the future, and that major MNCs have to prepare for that fact. Mrs Reed furthered the idea that a global leader would have to be able to understand a number of different cultures and have a certain respect for them. Furthermore, they are all but obliged to possess a certain sense of business. Complicating the situation further, she stated that the difference to work in New York compared to inner China might be severe, at least from a westerner's perspective. Mr Sullivan 
had a similar line of reasoning, stating that a potential global leader has to be able to cope with issues such as working across time zones and building solid relationships with employees from another culture. He also emphasized on the fact that a global leader should be an individual not with the belief that he or she is superior to his or her peers, but rather feeling the urge to take on bigger responsibilities.

The knowledge and prerequisites of the hypothetical global leaders mentioned by the Circfor HR managers was not a homogenous list of attributes, but very context dependent and had to be adapted based on the area in which they are supposed to be working. Mrs Reed emphasized that if a potential global leader were to be moved abroad but lack skills in a certain area, he or she would in all likelihood have a team present to compensate for any lack of knowledge in the relevant area.

In conclusion, Circfor does not employ the term global leader as such, perhaps due to the fact that it necessitates its higher-level managers to be able to handle international issues, an aspect which is thus assumed by the company elites. In parallel to the already existing literature of global leaders in theory, the definition of a global leader also could not be exactly defined within the framework of the company, though its hypothetical makeup mirrors that stated in the beginning of this thesis: "a high level manager capable of understanding the nature and importance of multiple cultures, while at the same time possessing at least a rudimentary understanding of business management" based on interviews conducted with the four HR managers. It should also be noted that when asked about future challenges for the company in the field of HR development, talent management and succession planning, none of the interviewees stated that a lack of top managers was an issue to be considered. Indeed, Mrs Reed stated that the opposite was the case in the lower levels. If this statement were to turn out true, it might suggest that the Circfor development process of its global leaders is an effective one.

\subsubsection{Development programs}

Though Circfor offers 17 development programs, most of these are not be described in this thesis due to reasons of relevance and space. Two of the most common programs attended by the interviewees are the GOLD and the TED, both of which will be described below. The last program to be mentioned is the NODE seminar. 
The selection procedure for attending the different programs is based on performance dialogs and a planning and performance meeting between the employee and his superior, who discuss advancement and educational options, then come to a consensus regarding whether or not the employee should attend a development program. While the ultimate decision is up to the instigators of the program, employees can express their interest in attending a program they deem relevant to their own development.

The GOLD (Globally Oriented Leadership Development program) development program is naturally a pseudonym, but refers to a program within the Circfor group university with a name corresponding to the contents of this name. It was described by $\mathrm{Mr}$ Kelso as one of the company's flagships, available to employees of level 4-6 and aims towards the development of individual's leadership and business skills. It includes international aspects, highlighting the importance of a global mindset. Information gathered from the interviews indicate it also serves a culture-bearing function, using business and HR-related information in order to convey how and why certain methods are used and what considerations are important to ponder at the higher levels of the company.

Mr Sullivan revealed that the program also has a component of self-development, geared towards understanding oneself as a manager before leading others in a leadership position. Essentially, that could be one reason why higher level managers are not targeted for this education - having reached managerial level 4 or above, one might be expected to have mastered these secrets. Secondary data states that the program aims to offer managers of high professional capacity advanced methods to guarantee continuous development. Furthermore, topics related to strategy, people management and leadership are included as well.

The TED (Top Echelon Development program) development program is also a pseudonym for a program whose content is reflected in this made-up abbreviation. It is available for managers between levels 1 and 4 , its content focusing on topics like strategic innovation, planning for the future et cetera, with the exact topics not staying the same from year to year. Statements from Mr Kelso and Mr Sullivan indicate that the program is mandatory for its target group, namely top management such as business area presidents and business area main managers. Mr Bester contributed with similar information, but explained that the TED program had a large impact on available networking abilities. Not merely enabling increased connections, the program also made it possible for different managers to understand other 
business areas, their customers and procedures. Furthermore, he described the TED program as being important for being an effective superior within Circfor. Mr Sheridan commented that participating in the TED program gives insights into the inner workings of the company.

The NODE (Newcomer Orientation and Development Education) program is an introductory seminar, aimed at employees between levels 3 and 5. Its content introduces employees to Circfor's organizational structure and presents lead managers within the different business areas. Mrs Ivanova, having attended the seminar herself, stated that, among others, the CEO of the company held a speech, after which a number of business area presidents presented themselves and the strategies and customers of the respective areas. Secondary data confirms the aim of the seminar to offer increased information about the group's strategy, goals, and business models.

\subsection{Individual perceptions of development programs}

\subsubsection{Level 2 managers}

Level 2 managers are higher-up managers in the company responsible either for their own business area, or for a higher-up position within sales, HR or other functions, and report directly to the president/CEO of the company. A total of three of the interviewed individuals were defined as being on level 2; namely Mr Sinclair, a business area manager; Mr Bester, a high-level purchasing manager, and Mr Sheridan, another business area manager. All three interviewees had taken part in the TED development program, which was thus in focus during the interviews. The GOLD development program is geared toward managers at levels 4-6, meaning that level 2 managers are not supposed to partake in it. However, it is possible for a level 4 manager to advance higher up over time, and as such these managers may have participated in the GOLD program earlier.

- Mr Sinclair

"In the final analysis, it [what drives you forward] is that you yourself develop and are excited by something, interact with effective people..."

Revealing a direct interest in the TED, the fact that he voluntarily would have attended the program seems rather unambiguous. Mr Sinclair repeatedly mentioned that one of the major 
benefits of the TED programs was the increased networking coming from the large number of higher executives invited to partake in this program. Also important was the competency development, the possibility to learn something specific at the program, then return to his normal work situation and apply it. He indicated that he had attended a number of superfluous non-mandatory programs as well, with the goal of being able to improve his performance at work: again relating to discovering tools applicable at his job. Asked if this development program would reach his expectations, he gave a resounding positive response, indicating a strong belief in the efficiency of the program. His response to whether or not the program could be somewhat difficult or whether he could complete the program successfully, he responded that though not having attended an abundance of programs, the ones he had attended had been of high quality, and his worries were quite limited.

In terms of values and overall driving force, he emphasised being in the thick of things, the will to be present when decisions are made, wanting to see results and enjoying a challenge. However, he referred to the social aspect to a large degree, mentioning the importance of being involved in a good team, meeting people and also highlighted the international aspect of the working situation. Asked if he would participate in another development program, he stated the importance of fostering communication between top level and lower level managers and that such programs would be of interest to him, leading to the likely conclusion that he would be intrinsically motivated by the efficiency of his work. He explained that due to his satisfaction with the company, the likelihood of him leaving the company is small, bar extremely negative development either in the personal plane or for the company as a whole. In his words (translated from Swedish), “...it would have to be unique”.

\section{- Mr Bester}

$$
\begin{aligned}
& \text { “... it's important that you feel you can call anyone at any time. } \\
& \text { [...] It's much easier to do once you've shared a beer with the boss } \\
& \text { before." }
\end{aligned}
$$

Mr Bester began the interview by stating that participation in the TED-program was mandatory, but did not comment on whether he would attend or not, were it optional. The expected returns from the program he stated to be increased networking opportunities and the possibility to be a better leader of his group, stating that this is an area in which one can 
always improve. The social aspect of the program was somewhat pronounced towards the end of the interview when he stated that one of the main outcomes was the increased networking opportunities and meeting new people, which can facilitate communication. The difficulty level of the program was not an issue beforehand, though he did admit to the fact that a certain degree of effort was required during participation.

He related his job motivation to developmental questions, seeing how his work could impact those around him and being able to trace the results of his actions. Connecting to the GOLD, which he had attended years before doing the TED, he noted that he attended voluntary in order to develop his understanding of areas outside his field of expertise. It thus appears that Mr Bester's stated reasons for attending resonate with his intrinsic job motivation. He ended his statement by concluding that because of his high level, he would likely not consider switching from his current job position unless offered the chance of doing a similar developmental trip in another company.

- Mr Sheridan

“... it's a combination of business-related questions, sometimes technical, dealing with people from different places in the world and so on, that mix of parameters is exciting and it enthusiasms me. In the end I'm very enthusiastic by these issues, almost a part of my self-fulfilment, I love working with it, definitively the main reason [for my motivation]."

Mr Sheridan stated that he would have voluntarily attended if given the option and that he expected the development program to give him an insight into the effects that different decisions could have in the long run, so as to be able to make more accurate decisions in the future. In short, he expected the benefits of a TED-like program to be the possibilities to perform effectively. When asked whether he had any considerations regarding the difficulty of the program, he responded that those concerns were minimal, partly because of him having attended similar programs in the past, partly because he experienced that those programs had indeed increased their communicative capacities.

Mr Sheridan stated that creating measureable results, being of constructive use, getting feedback on his results and reaching goals was of supreme importance to him, and described 
himself as a rather competitive person. He also pointed out that having a pleasant organizational culture and environment was very important. Additionally he noted that the technical development and questions surrounding his work in combination with dealing with people from across the world - essentially his job profile - was tied to his self-fulfilment.

Towards the end of the interview, he talked about what programs he would like to attend in the future, again expressing a wish to partake in programs developing his own skills for efficiency reasons, stating one important area to be the development of computer-related issues, an area where he fear he might not stay in the loop. Concluding the interview, he was asked what could incite him to leave Circfor, a question to which he responded that that could only occur if something "really big" were to appear, something which would constitute a true challenge, suggesting that Mr Sheridan likely would be motivated more by intrinsic rather than extrinsic reasons. What can be extrapolated is that the intrinsic motivation for taking part in these development programs appears to be a wish to improve his own efficiency and the wish to feel like his contributions matter.

\subsubsection{Level 3 managers}

Level 3 managers refer to those individuals who report to the level 2-managers. The level 3 managers are eligible for the TED development program, but are too advanced to be allowed access to the GOLD development program. These three individuals have had rather different training opportunities and experiences, and have attended no common development programs. Mr Allan is a high-level manager related to acquisitions and sales; Mrs Winters is HR vice president in the same business area as Mr Sinclair; and Mr Cole is responsible for the group finance function.

- Mr Allan

[What is important is] that it [work] is varied, new intellectual challenges, having a constant, continuous cooperation with your superior, having interactivity. When you just stand around it gets boring, unmotivated. It's hard to do standardized things all the time. 
Mr Allan voluntarily attended the GOLD program because of his own interest. His field of expertise being in the field of finance, he mentioned that the part in the GOLD program relating to factors such as psychology and HR was rather interesting, while the financial part of the program presented little new knowledge to him and thus was of less importance. He mentioned that the psychology and HR training was “... very interesting” and "Nothing I'm comfortable in normal life". Though he found the program interesting, he did not expect it to be overly beneficial.

He mentioned attending the program because of the networking opportunities in combination with the opportunity to attend something new and rather exciting. Furthermore, he noted that he might not be the main target group for the education and that he might not get a great deal out of the program, its focus being geared toward transmitting Circfor values such as anticorruption and attaining a "Circfor mindset". Possibly, his motivation to take part in the program might be seen as a chance to increase his networking abilities (which, along with salary, was a primary motivator). Asked whether he had expected the program to be inherently difficult, he responded that he felt like he was "in deep water" and was somewhat uncomfortable with the first part of the program.

He stated that the combination of freedom under responsibility was one of the major factors behind his drive. He also mentioned diverse working tasks, new intellectual challenges and continuous communication with one's superiors to be the most important factors for his own motivation. When asked what improvements could possibly be done to his working positions, he stated a preference to include more operational tasks in his work, perhaps shifting to another position within operations rather than his current positions at headquarters.

This seeming desire to switch work focus was somewhat echoed in a number of statements in when asked to mention positive aspects of his work, at the end arriving at the conclusion that working close to the executive power and with qualified individuals was likely the most positive aspects of his job. A somewhat enthusiastically lacking tone was present during the interview when discussing promotion opportunity directions and when discussing primary benefits of the job, possibly reinforcing the assumption that the current position is not optimal for this particular employee. Somewhat unprecedented in these interviews, Mr Allan also did not indicate a wish to participate in any particular development program. 
- Mrs Winters

I've always been working in a global mix. I wouldn't even contemplate a job at a local level. I think it's important to be careful with oneself: "is this really the area in which I want to work?"

Mrs Winters, being rather recently introduced to both Circfor and her new position, has not attended any development program at Circfor. Lacking a clear way to investigate her interest in Circfor-offered programs, her motivation regarding programs attended in other companies was investigated instead. Apparently, her main motivation towards attending development programs as such stems from her belief that they can result in her development as a leader with regard to leadership abilities and her role in management. She did not expect a development program to lead her to new positions, but rather that a developmental program might increase her efficiency at work, which in term might benefit her career. Additionally, she mentioned the possibility that she might consider taking the role of her superior in a number of years, for which she would require additional experience in a number of fields. Though this experience might require extensive effort on her part, the concept was considered a challenge rather than an obstruction or a threat.

Swiftly stated her main motivation to be her need for recognition by colleagues and superiors and being appreciated for what she does, in combination for a need of feedback. When the difference between her own work and others becomes overt, she stated that her motivation spiked. While on the subject, the concept of developmental opportunities was brought up, though lack thereof would become a problem only if manifested in a longer term perspective, across years rather than months. In a similar vein, her pride in her work and her company were also significant for explaining her motivation, giving an example of a former company of hers which offered its employees massive amounts of traveling opportunities. Furthermore, she brought up the fact that her workload was rather high; she has many tasks to deal with simultaneously, yet enjoys the support of colleagues and superiors alike, and does not experience severe job stress because of the job allotted. Ending this trail of thought, she concluded that the closeness to her colleagues was of fundamental importance. In conclusion, she said "Yes, [I] love my job." 
- Mr Cole

... [I am] proud to be working at Circfor. I suppose that's one motivator. In some way you want your company to develop, you are a part of it. [...] I suppose it's a motivator to deliver things that someone else can appreciate.

Being a level 3 manager and having occupied his current position since 2006, Mr Cole has attended the TED development program four times. Though he declared that his attendance in the TED was not optional, when asked if he would attend voluntarily he gave a positive response about its content, but did not overtly state that he would attend, were it voluntary. Though he viewed the benefits of the program to be mostly its developmental potential in terms of workplace efficiency, he also saw the increased networking opportunity as one of the major benefits of the program itself. He was not concerned about the difficulty of attending a further development program.

He was adamant in stressing his strongest motivational factor to be company pride, a will to see the company excel as he saw himself as part of that company. He also stated that it was rewarding for him to be able to deliver something of value that others could use. That in combination with the need for new experiences and his self-stated propensity to enjoy working paints the picture of an employee enjoying diversified tasks in high abundance. Furthermore, it became apparent that Mr Cole had a fondness for working at Circfor because of the environment at the firm and the mood between the employees. Further factors included the efficiency of the company itself, giving the chance for him to hold a positive view of the company. While the aspects stated above are rather positive, Mr Cole also stated that the developmental possibilities at Circfor were somewhat limited due to its size and that his satisfaction with his position tends to ebb and flow with certain periodic happenings. Besides the TED, he expressed interest in attending the GOLD, but concluded that he was too advanced in both years and management levels to be in the intended target group. Interestingly enough, Mr Cole is involved in the GOLD as a lecturer. Asked what could make him leave Circfor, he concluded that barring a rather negative development within Circfor, it would appear rather unlikely, referring partly to his age. 
In closing, Mr Cole's desire to participate in the development programs in order to increase his workplace efficiency and to increase his networking opportunities appear to correspond well to his drive to perform well for the firm, but the connection to his need for differentiated tasks is unclear.

\title{
4.2.3 Level 4 managers
}

Level 4 managers refer to those individuals who report to the level 3 managers. The level 4 managers are eligible for both the TED and the GOLD development programs, but also for a number of others, for instance the NODE. There are a total of three interviewees at level 4; Mr Garibaldi, responsible for development and implementation of various talent management functions and a subordinate of Mr Sullivan; Mrs Alexander works with group finance control; and Mrs Ivanova, who is a purchasing manager.

\section{- Mr Garibaldi}

\author{
In doing this job the main motivation is really to create something \\ that is useful for people. Create something that can give tools to the \\ people, not something vague. [...] So the main motivation should \\ be that for any staff function. If we can create something useful, we \\ reach our goal.
}

Mr Garibaldi is involved in the developmental aspects of the GOLD program, and has attended it repeatedly in an educational capacity rather than as a participant. He tended to partake in its execution in an informal capacity in order to meet the attendees in hopes of boosting the interaction and extracting a certain degree of joy.

For his own development, he voluntarily attended an educational program in the field of psychology and in an internal Circfor education in the field of manufacturing and purchasing. When asked about his reason for attending, he mentioned not only an interest in the concepts in the programs themselves, but he also expected them to be beneficial for him in his day to day interactions with customers. Not delving into specific reasons, he was rather direct in stating that he did not consider the possibility of the programs being advanced or difficult enough to derail his chances of fulfilling their curriculums. 
Mr Garibaldi has been responsible for training and development on group level for three years. Early in the interview he stated his motivation being tied to creating something of concrete use to individuals and ascertain that the product he delivers is valuable. As such, he stressed the need to understand the business model of his customers and their way of thinking. He also revealed that his job necessitates the theoretical understanding of the customer's development needs, which if successful translates into self-enrichment, which is of high importance to him. He expressed a will to attend a field-specific education, interesting to him for the singular reason of being rather different to his main field of expertise.

Towards the end of the interview, the international nature of the Circfor organizational structure was brought up. Discussing what he absence of international issues would have on his job, he made it abundantly clear that if his job were not of an international nature, he would consider the job rather empty. As such, apart from the job losing its international characteristic, the only scenario in which he might consider leaving his job would be if a job with representing an extreme challenge were to appear. In conclusion, he commented that the job itself has always been his main motivation.

\section{- Mrs Alexander}

It's when I can wake up in the morning and think to myself:

"Wow, it's so much fun to go to work!" That's the most important thing.

Being new to Circfor, Mrs Alexander has not attended any development program, though she has expressed interest in the GOLD program, and was indeed supposed to attend it, had it not been for a schematic oversight. She did however indicate a continued interest in attending, citing her desire to "learn new things"; preferably tools which could end increase her efficiency at work. She also expected the GOLD program would give her a better understanding of her work. Showing similar considerations as many interviewees before her, she stated that the networking opportunities and meeting new individuals were also relevant for her being interested in the program.

Unwilling to submit a single motivational factor as most important, she rather stated it to be a combination of enjoying her job, her colleagues and getting along well with her superior. 
Though her first year at Circfor has related to a high degree to getting to know the company, she expects the next year to be a year of personal development. This particular factor was mentioned several times as well: the opportunity to grow and having challenging tasks to perform. The international aspect of the company and her job also appear to represent a significant motivator, though perhaps not in the traditional sense. Despite mentioning the international nature on three separate occasions, she made it abundantly clear that she is unwilling to move abroad due to family reasons. She also sees few obvious advantages to moving abroad, her situation already being characterized by international contacts and responsibilities. As such, being apparently satisfied with her position, she could conjure up few scenarios compelling her to leave her current job, though mentioning a severely increased salary or the replacement of her superior as possible reasons for altering that decision.

- Mrs Ivanova

For me, I'm very result focused, I want to deliver something. I don't really like to talk fluffy. There is a goal, and I achieve it, and I will be recognised. In the beginning in Sweden, I had problem to adapt to some sort of Swedish, probably traditional methodology.

Mrs Ivanova, being somewhat new to the company, has attended a total of two development programs; the NODE seminar and a secondary development program specific to her field of expertise. She stated quite overtly that she would like to join the NODE whether it was voluntary or not, because it gives the employees an opportunity to use common practices and methods when working, thus viewing it as a work tool. Additionally, she expressed interest in the GOLD, viewing it as an excellent preparatory program for future advancement in the field of management and all but a prerequisite for ever becoming a manager herself. She explained that the way managers think would be rather beneficial to understand, what factors to focus on, but also she expected and was interested in an increasing knowledge in regards to how to relate to individuals of different cultures, ages and professional areas.

Furthermore, the networking opportunities provided by the program she also saw as rather desirable. Concluding her statement on the subject, she mentioned that the overall purpose of attending the program would be to broaden her views. Her wish to attend the GOLD 
corresponds well to her expected outcome of it (related to performance increase), and resonates with her overall motivation of performing well and being recognized.

She stated early on that she was rather result-driven, deriving most of her satisfaction and motivational power from the results she deliver. Appearing often in the interview was topics relating to the importance of being recognized, being seen and performing better than her peers. Rather overtly, she also noted that the Swedish culture was somewhat complicated to adapt to at first, seeing it as not putting enough emphasis on the results she could produce and the need for development on her part. She saw the developmental programs attended as being beneficial for maximizing potential communication between her and her peers, which will be discussed further below. A second part of what motivates her was the opportunity to do different tasks and meet different people. The fact that her current position allows her a rather high degree of freedom seems to resonate with her desire to have control over her own work situation. This also relates to her work load, stating that she herself regulates the degree of work she has to handle. As a conclusion, she stated that as long as she has a job, can deliver something important and can work with different people, she will be rather satisfied.

\title{
4.2.4 Individual at unknown level
}

One interviewee was not certain of to what level he belonged. Mr Franklin is rather new at his position, yet his task of high-grade involvement in other development programs makes it unlikely for him to be especially far down the hierarchy.

\section{- Mr Franklin}

\author{
[The reason for attending development programs] would be related \\ to knowing how Circfor view their future leaders, what's important \\ in a leadership position, as a Circfor leader. Not so much about my \\ daily work more effective, but rather what Circfor thinks are good \\ traits for a leader and how I can become more "Circforified".
}

Mr Franklin attended the developmental program for its Circfor-specific aspects. Rather than being interested in contextually unbound programs in the field of leadership, he was interested in what qualities Circfor considered relevant for highlevel leaders and managers. Not specifically talking about the efficiency-related benefits of development programs, he 
reflected on the fact that leadership is bound by the organizational culture, and that these programs act as culture bearers, thus informing him what traits could help him become a more effective leader within the Circfor framework. Besides the beneficial outcomes such a program could have on himself and his performance, Mr Franklin also noted that education as such brought a certain degree of satisfaction, and they all bring some concepts relevant to his current job, specific or not.

Mr Franklin pointed out that part of his drive was seeing the results of his work, the satisfaction of seeing something happen, being able to deliver something or make something else better. When discussing the specifics of his current job, he mentioned that he was supremely satisfied in his position because he had the opportunity to increase the efficiency of the customer departments he worked with, or "to help departments with [their] operational efficiency..." He also explained that not only did he want to be able to see the fruit of his own work, but to conclude that his superior would recognize his effort and participation in his work. The other motivational factor mentioned was the satisfaction gained when seeing other people grow and having a satisfying working position. On the other side of the motivational spectrum, he stated lack of work to be done in combination with lack of interesting tasks to be the most de-motivational factors in his mind. Avoiding repetitive tasks and following the same routines was thus a concern for Mr Franklin, lest he would lose his energy and enthusiasm for his job. It is noteworthy that the international and travelling aspect of his job was of little interest for him, boiling the concept down to time spent at the airport and the negative impact it would have on his time spent with his family. Quoting him, he stated that "If there were a similar assignment in Alingsås I would have gone there, that it happens to be in Poland or Holland is not that relevant or important".

The question of interest in future development programs brought him to mention the TED development program, soon concluding that he was uncertain whether he fit the target group, stating that he might perhaps aim at another program geared towards leadership development, though he was uncertain which. Faced with the prospect of mentioning what could incite him to leave his current job, he explained that his current one was all but ideally suited to his family and professional situation, making the likelihood of him leaving extraordinarily miniscule. 


\subsection{Findings overview}

The information gathered from the presentation above is rather extensive, and its content is rather complicated to fully absorb without the results being stated in the form above. Nevertheless, in the interest of clarity and simplicity, a table presenting the most relevant findings of the interviews would be most beneficial. Such a table is thus presented below.

Table 3 - Summarized findings

\begin{tabular}{|c|c|c|c|c|}
\hline & Mr Sinclair & Mr Bester & Mr Sheridan & Mr Allan \\
\hline $\begin{array}{ll}\text { First } & \text { level } \\
\text { outcome } & \end{array}$ & $\begin{array}{l}\text { Successful } \\
\text { program } \\
\text { attendance }\end{array}$ & $\begin{array}{l}\text { Successful } \\
\text { program } \\
\text { attendance }\end{array}$ & $\begin{array}{l}\text { Successful } \\
\text { program } \\
\text { attendance }\end{array}$ & $\begin{array}{l}\text { Successful } \\
\text { program } \\
\text { attendance }\end{array}$ \\
\hline $\begin{array}{ll}\text { Second } & \text { level } \\
\text { outcome } & \end{array}$ & $\begin{array}{l}\text { Increase } \\
\text { knowledge, } \\
\text { broaden } \\
\text { network. }\end{array}$ & $\begin{array}{l}\text { Learn more } \\
\text { about the group, } \\
\text { develop oneself. } \\
\text { Leadership } \\
\text { development, } \\
\text { broaden } \\
\text { network. }\end{array}$ & $\begin{array}{l}\text { Better } \\
\text { understanding of } \\
\text { situational and } \\
\text { technical } \\
\text { matters. }\end{array}$ & $\begin{array}{l}\text { Social } \\
\text { interaction. } \\
\text { Expected little } \\
\text { outcome. }\end{array}$ \\
\hline $\begin{array}{l}\text { Intrinsic } \\
\text { motivation }\end{array}$ & $\begin{array}{l}\text { Good team, } \\
\text { work with } \\
\text { people, global. }\end{array}$ & $\begin{array}{l}\text { Develop self } \\
\text { and others. } \\
\text { Make a } \\
\text { difference, } \\
\text { develop tools. }\end{array}$ & $\begin{array}{l}\text { Technical } \\
\text { aspects, } \\
\text { understanding, } \\
\text { mix of } \\
\text { parameters. } \\
\text { Challenges. }\end{array}$ & $\begin{array}{l}\text { Intellectual } \\
\text { challenges, good } \\
\text { interaction, } \\
\text { freedom. }\end{array}$ \\
\hline $\begin{array}{l}\text { Voluntary } \\
\text { attendance }\end{array}$ & Yes & Yes & Yes & Yes \\
\hline $\begin{array}{l}\text { Further } \\
\text { program } \\
\text { interest }\end{array}$ & Yes & Yes & Yes & No \\
\hline
\end{tabular}

\begin{tabular}{|c|c|c|c|c|}
\hline & Mrs Winters & Mr Cole & Mr Garibaldi & Mrs Alexander \\
\hline $\begin{array}{ll}\text { First } & \text { level } \\
\text { outcome } & \end{array}$ & $\begin{array}{l}\text { Successful } \\
\text { program } \\
\text { attendance }\end{array}$ & $\begin{array}{l}\text { Successful } \\
\text { program } \\
\text { attendance }\end{array}$ & $\begin{array}{l}\text { Successful } \\
\text { program } \\
\text { attendance }\end{array}$ & $\begin{array}{l}\text { Successful } \\
\text { program } \\
\text { attendance }\end{array}$ \\
\hline $\begin{array}{ll}\text { Second } & \text { level } \\
\text { outcome } & \end{array}$ & $\begin{array}{l}\text { Personal } \\
\text { improvement, } \\
\text { skill } \\
\text { improvement. }\end{array}$ & $\begin{array}{l}\text { Meet people, } \\
\text { perhaps learn } \\
\text { something. }\end{array}$ & $\begin{array}{l}\text { Useful for } \\
\text { development, } \\
\text { useful for my } \\
\text { job. }\end{array}$ & $\begin{array}{l}\text { Understanding } \\
\text { the company, } \\
\text { network, social. } \\
\text { Developing } \\
\text { work skills, } \\
\text { more effective at } \\
\text { work. }\end{array}$ \\
\hline $\begin{array}{l}\text { Intrinsic } \\
\text { motivation }\end{array}$ & $\begin{array}{l}\text { Pride, delivery, } \\
\text { make a } \\
\text { difference. }\end{array}$ & $\begin{array}{l}\text { Develop } \\
\text { company, } \\
\text { Deliver } \\
\text { something that's } \\
\text { appreciated. }\end{array}$ & $\begin{array}{l}\text { Responsibility, } \\
\text { create } \\
\text { something } \\
\text { useful, the job } \\
\text { itself. }\end{array}$ & $\begin{array}{l}\text { Fun to go to } \\
\text { work, } \\
\text { colleagues, } \\
\text { challenges, } \\
\text { developing }\end{array}$ \\
\hline
\end{tabular}




\begin{tabular}{|l|l|l|l|l|}
\hline & & & & herself. \\
\hline $\begin{array}{l}\text { Voluntary } \\
\text { attendance }\end{array}$ & Most likely & Unknown & Yes & Yes \\
\hline $\begin{array}{l}\text { Wish to attend } \\
\text { further } \\
\text { program }\end{array}$ & $\begin{array}{l}\text { No (perceives } \\
\text { no applicable } \\
\text { ones available) }\end{array}$ & Maybe & Yes & Maybe \\
\hline
\end{tabular}

\begin{tabular}{|c|c|c|}
\hline & Mrs Ivanova & Mr Franklin \\
\hline $\begin{array}{ll}\text { First } & \text { level } \\
\text { outcome } & \end{array}$ & $\begin{array}{l}\text { Successful } \\
\text { program } \\
\text { attendance }\end{array}$ & $\begin{array}{l}\text { Successful } \\
\text { program } \\
\text { attendance }\end{array}$ \\
\hline $\begin{array}{ll}\text { Second } & \text { level } \\
\text { outcome } & \end{array}$ & $\begin{array}{l}\text { Common way of } \\
\text { working. } \\
\text { Understanding } \\
\text { important } \\
\text { factors for } \\
\text { managers. }\end{array}$ & $\begin{array}{l}\text { Understanding } \\
\text { leadership } \\
\text { factors, tailoring } \\
\text { leadership style. }\end{array}$ \\
\hline $\begin{array}{l}\text { Intrinsic } \\
\text { motivation }\end{array}$ & $\begin{array}{l}\text { Results driven. } \\
\text { Being seen, } \\
\text { recognized. } \\
\text { Work together } \\
\text { well with } \\
\text { colleagues. }\end{array}$ & $\begin{array}{l}\text { See things } \\
\text { happening, have } \\
\text { an effect. See } \\
\text { things develop. }\end{array}$ \\
\hline $\begin{array}{l}\text { Voluntary } \\
\text { attendance }\end{array}$ & Yes & $\begin{array}{l}\text { Not applicable } \\
\text { (no program) }\end{array}$ \\
\hline $\begin{array}{l}\text { Wish to attend } \\
\text { further } \\
\text { program }\end{array}$ & Yes & $\begin{array}{l}\text { No (perceives } \\
\text { no applicable } \\
\text { ones available) }\end{array}$ \\
\hline
\end{tabular}




\section{Analysis}

The analysis part consists of four sub-headings. The first section interprets the responses from the interviews from the perspective of the expectancy theory framework. The second section takes the view of the participants, highlighting and analysing the reasons for their participation in the actual programmes. More than merely stating the reasons given by the participants for attending the programs, their motivations will be interpreted via the expectancy theory framework in order to understand their reasons for attending. The third section analyses the content of the available development programs, presenting the view of the HR managers. Hence, it will handle information from the HR managers as well as the secondary material gathered in the form of documents. The object of this section is to explain the purpose of the developmental programs and how they are aimed to increase employee performance and train them to become more successful. The fourth section will serve as a mop-up section, presenting information uncovered in the interviews that is relevant to research about global leader development, yet not directly related to the expectancy theory.

\subsection{Interviewee motivations and the expectancy theory framework}

This section first gives an individual view of the different factors relevant for the employees' willingness to attend the program. Though stated in the findings section, they have not yet been analysed in context of the employees' situations or been interpreted through the expectancy theory framework. As a result, the motivational strengths of the individuals to participate in development programs will be revealed in this section. It should also be noted that the preceding section (section 5.2) will address highlighted factors in more detail.

As mentioned briefly in the methods-section, the findings from the interviewees have been interpreted to allow them being presented in a simple for in a table like the one below. In the interest of clarity, the results of the questions regarding expectancy and instrumentality will be presented as either convinced, somewhat convinced or not convinced. The valence answer will be interpreted as either overt, somewhat overt or not overt. The motivational force - that is, the strength of the motivation to attend in development programs - is coded as strong, average or weak. Each interviewee has a short description of his or her interpreted motivation, analysed using the expectancy theory framework. 


\subsubsection{Level 2 managers}

- Mr Sinclair

The factors motivating Mr Sinclair to participate in development programs appeared rather clear: increase knowledge relevant to his own position while simultaneously expanding his networking opportunities. He also stated that he had no concerns regarding whether he could successfully complete the development program he had partaken in (the TED), citing the fact that he had attended development programs before. He also responded by saying "Yes... absolutely", when asked if he believed the program would bring him the outcomes he expected. When tasked to state his overall work motivation, he mentioned enjoying being a boss, working with people, talking to new people, the fact that he was somewhat inpatient and wanting to reach results quickly. Below is a short overview of Mr Sinclair's factors.

\section{Convinced expectation $*$ convinced instrumentality $*$ overt valence $=$ Strong motivation}

Since expectancy, instrumentality and valence were all strongly indicated by the interviewee, it could be expected that he has a strong motivational force. Based on the fact that he stated an overt will to partake in another development program, combined with his statement that he would voluntarily attend the TED if given the option, this does not appear unreasonable. Though gauging interviewees motivational strength cannot be done precisely merely via interviews, it should also be mentioned that Mr Sinclair after the interview noted his family situation to be rather compatible with his current work position and was overtly rather joyful during the interview.

\section{- Mr Bester}

$\mathrm{Mr}$ Bester attended the program for the chance of increasing networking opportunities, improving his efficiency as a leader and for the social aspect, and anticipated no problems when asked whether he could successfully complete the program, though expecting the program to demand some degree of effort. Having participated in developmental programs before, he expected the program to deliver the outcomes offered. Asked about his intrinsic motivation, he mentioned the chance to develop himself and the people around him and simply making a difference, do well at his job. 


\section{Convinced expectation $*$ convinced instrumentality $*$ overt valence $=$ Strong motivation}

Mr Bester can be expected to have strong work motivation. That he stated an interest in further development programs may support this thought, but it should be noted that Mr Bester did not state a willingness to attend the program, had it been voluntary at the time. Mr Bester mentioned his work situation to be somewhat lacking socially, working with merely two colleagues, and that the office felt "empty" sometimes. Given the fact that one of his main motivational factors was social interaction and the fact that he expected and believed the programs would deliver social benefits, his motivation for attending them should be strong. Nevertheless, the networking aspects and development aspects appear to be central and perhaps more easily confirmed.

- Mr Sheridan

In this case, the possibility of being more effective in the job situation appeared to be the reason for attending the TED, and Mr Sheridan had little doubt that he could successfully complete the program. Though not overtly stating his belief that the development program would make him become more effective, his statement that previous programs had done so and that they had gotten better over time seems to indicate high instrumentality. In terms of overall motivation, Mr Sheridan mentioned clearly that, the most important factor was doing well at his job and reaching his goals. As this was also his expected outcomes of the program, it can be inferred that his valence would be high.

\section{Convinced expectation $*$ convinced instrumentality $*$ overt valence $=$ Strong motivation}

Yet again an employee with expected high motivation is presented. The fact that Mr Sheridan stated an interest in attending the program even if it were not mandatory strengthens this view, and the fact that he expressed overt interest in further development seems to reinforce this belief.

It thus appears that all level 2 managers where strongly motivated to attend further development programs, which merits two comments. First, the possibility that their interest is somehow correlated with their position. Interestingly, these three interviewees mentioned no 
common reasons for attending the programs. Though the risk always remains that interviews can be misinterpreted or incomplete, the fact that no common factors was found presents an anomaly. The possibility exists that the higher-up positions could hold an explanation, which brings us to the second comment. Mr Kelso, the head HR manager, stated that higher-up managers like these were less inclined than lower-level managers to be interested in development programs, believing themselves to be fully developed. Either he was incorrect in his assessment, or these three managers simply do not fit that bill. Thirdly, only one of these managers related to the international aspect of business, and then only in passing. One might expect more enthusiasm from managers at these levels. Again, the possibility exists that they perceive no need to develop international talents, but the fact that international experience, work or travel does not explicitly appear in their intrinsic motivation does present an anomaly.

\subsubsection{Level 3 managers}

\section{- Mr Allan}

Mr Allan attended the program for two reasons. First, he believed that his networking opportunities could be increased if attending the program. Second, the GOLD gave him a chance to attend something different from his normal field of expertise, making it exciting. While not openly stating a perceived difficulty in attending the program, he noted several issues regarding the nature of the program and handling its content, in combination with his statement that some issues covered in the program was "Nothing I'm comfortable in normal life". Furthermore, he did not expect the program to be overly beneficial in terms of outcomes, though stating its content to be interesting. His overall motivation he related to intellectual challenges, good interaction and freedom.

\section{Somewhat convinced expectancy * unconvinced instrumentality * somewhat overt valence $=$ average motivation}

With both expectancy and valence being interpreted as average and his instrumentality being unconvinced, the motivational force of this particular employee shows indications of dissatisfaction. This interpretation is supported by the fact that he expressed little interest in attending further development programs, while at the same time stating that he would have attended the GOLD, were it voluntary. It should be noted that he stated knowing exactly 
where he might be promoted to, and further that that position is desirable and that he would need little or no development to attain it. Several statements in the interview indicate some degree of dissatisfaction on part of the employee, although it should be duly noted that he had no wish to complain. This also furthers the idea that the employee believes the development programs not to be applicable for his current position, that another program might be more beneficial for the desired position.

- Mrs Winters

Another somewhat different employee, Mrs Winters has attended no development program within Circfor. Being a level 3 manager, the TED should be available, though she stated that no programs were overtly applicable to her, though it should be admitted that her short time at Circfor and possibly (though, of course unbeknownst to us) her performance appraisals may explain her not participating in this program. As such, her interest in development programs will have to be gauged from information taken from previously attended programs. As it appears, her reasons for attending previous programs were connected to her belief that they could develop her leadership abilities and management efficiency. Her expectancy for the development program should be categorized as convinced, though the instrumentality is harder to define, stating that a development program would not lead to a promotion, but rather merely improve her performance. Though it appeared she believed that the development programs would deliver, her intrinsic motivation related more to her performing efficiently, delivering something useful and getting recognition for her work, in combination with working tightly with her employees. Her motivational formula - for programs attended outside Circfor - is as follows:

\section{Convinced expectancy * somewhat convinced instrumentality * somewhat overt valence $=$ average motivation}

The perception that Mrs Winters would display strong motivation is backed up by her stating that she most likely would attend a development program if available, mentioning an interest in further language education, but influenced by no Circfor development program being available to her. 
- Mr Cole

Having occupied his current position for several years, Mr Cole has attended the TED program four times. Similar to previous interviewees, he mentioned the main benefits of the program to be related to operational efficiency and increased networking, and remained convinced that he could complete the program without complications. He did appear somewhat unconvinced that the program would deliver the expected results however, declining to comment. With his intrinsic motivation relating to pride in his company, a will to excel, enjoy different task and creating something of value, his overall driving force does seem to correlate at least partly with his expectations of the program.

\section{Convinced expectancy * somewhat convinced instrumentality * somewhat overt valence $=$ average motivation}

The expected average motivation on part of $\mathrm{Mr}$ Cole is somewhat furthered by his unwillingness to state whether he would attend another development program or whether he would have attended the TED, had it been voluntary. It is also possible that the fact that he is working with developing the GOLD content has an effect on his willingness to join development programs. However, having stated a will to join the GOLD as a participant if possible, one would expect a willingness to join the TED as well. However, his perception of joining the TED seemed limited, which might be mediated by the fact that he has attended it four times, though the focus of the TED does switch.

The level 3 managers all presented average motivational force, all of them citing lack of convinced instrumentality and non-overt valence, though the expectancy was in question only once. Mr Kelso predicted that higher managers often exhibit less interest in participating in developmental programs, believing themselves not to require such educations. This did not appear to be the case here, excepting possibly Mr Cole. A lack of relevant development programs did seem to be the case in all the cases however, assuming Mr Allan did not perceive training necessary because he desired another position. 


\subsubsection{Level 4 managers}

- Mr Garibaldi

Being responsible for certain developmental and implementation aspects of the GOLD program negates him from joining it as a full-fledged participant, while his level 4 managerial level makes it somewhat unlikely to have joined the TED, Mr Garibaldi's motivation to join development programs will be judged using the psychology-related educational program he joined recently.

The reason for attending his development program was the belief that it could be of constructive use in regards to efficiency, while he at the same time perceived the program to be interesting. The combination of being fully convinced that he could complete the program without problem, being ascertained that the program would yield what he expected it to and stating his intrinsic motivation to be his efficiency on the job, responsibility and the job itself, causes his motivational formula to be perceived as follows:

\section{Convinced expectancy $*$ convinced instrumentality $*$ overt valence $=$ strong motivation}

The above interpretation is mirrored by the fact that Mr Garibaldi stated an interest to both attend further programs, and the fact that he voluntarily joined this one. It should be noted however, that working as a developer and an implementer of development programs might affect his motivation. It should also be noted that Mr Garibaldi is the only participant in this study who stated to have a close family yet still be willing to work hard and risk limiting his chances to interact with them. Quoting him directly: "You travel a lot, I meet my wife quite little"

- Mrs Alexander

Citing no doubt that the GOLD could be completed successfully, Mrs Alexander stated a desire to join the because of the chance to increase her job knowledge, obtain tools which could boost her efficiency at work and help her to understand her work better. She also expected her networking opportunities to grow and anticipated social interaction to be enjoyable. Admitting her knowledge of the GOLD to be incomplete, she stated that she was 
not convinced that the program would lead to her expected outcomes, meaning that her instrumentality will not be interpreted as full. Her intrinsic motivation appeared to relate to enjoying her job, her colleagues as well as having a good relation with her superior. As such, her motivational formula becomes the following.

\section{Convinced expectancy $*$ somewhat convinced instrumentality $*$ overt valence $=$ strong motivation}

Again, because of a stated willingness to attend the development program willingly, the interpretation of the interviewee's motivation as strong appears likely. However, she was uncertain whether or not to attend an additional development program, mentioning that she had little information about them and not having attended programs before. It should be mentioned that this employee was one of the few interviewees to mention the international aspect, but noted that she was unwilling to move abroad, citing private and family reasons.

- Mrs Ivanova

For this employee, attending the NODE was an in-road prerequisite for working with the company. However, she had an interest in joining the GOLD development program, perceiving it to provide her with necessary information for her future career advancement. She also emphasised the understanding possessed by the higher-up managers and the knowledge relating to how to handle individuals of different age, sex and culture. Furthermore, the believed the networking opportunities to be beneficial, and saw the social aspect of participating in the program as desirable. Though being convinced that she could successfully complete the program, she did not overtly mention that she expected the development program to deliver all that she expected of it. In terms of overall motivation, she mentioned being result-driven and striving to deliver in order to be recognized. The benefits she expected from the program seem to be adequately related to her overall values, meaning an overt valence. Hence, the following formula would calculate her motivational force:

\section{Convinced expectancy $*$ somewhat convinced instrumentality $*$ overt valence $=$ strong motivation}


With instrumentality being the only factor not at maximum strength with this employee, the perceived strong motivation is not surprising. Looking at the level 4 managers as a whole, it appears again that they all present a strong motivation to take part in development programs. Two of the interviewees reported an instrumentality of mediocre strength however, most likely due to limited information on the development programs. Whatever the reason for limited information, the two both actively citing limited information on the programs. This issue will be addressed in section 5.3.5. It should be noted also in this section that there appears to be no lack of will to participate in developmental programs, just as Mr Kelso predicted.

\subsubsection{Individual at unknown level}

\section{- Mr Franklin}

Mr Franklin had not attended any developmental program, and can thus not be judged by it. Perhaps more interestingly, he was not interested in attending any addition training program, perceiving none of them to relate to his position, even though he was aware of them. He did state not to be uninterested in the concept of attending a development program, had it included the right mix of topics, such as leadership development. Unable to predict his chances of completing such a hypothetical program and also not being able to determine whether the program would deliver its promises, Mr Franklin's motivational force cannot be calculated.

It should be mentioned however that Mr Franklin was actively uninterested in a more international aspect, stating that the location of his assignment did not enter into consideration when choosing it. He did openly mention his supreme satisfaction with his job and geographical location, which might explain his lack of interest in international experience. It does not explain his lack of interest in development programs however, which is rather assumed to be based on his perception that no applicable programs are available to him.

To provide an overview of the data presented in this section, a table has been created presenting the data not already presented in table 3 . 
Table 4 - Motivational force

\begin{tabular}{|l|l|l|l|l|}
\hline Expectancy & Mr Sinclair & Mr Bester & Mr Sheridan & Mr Allan \\
\hline Instrumentality & Convinced & Convinced & Convinced & $\begin{array}{l}\text { Somewhat } \\
\text { convinced }\end{array}$ \\
\hline Valence & Overtly & Convinced & $\begin{array}{l}\text { Somewhat } \\
\text { convinced }\end{array}$ & Unconvinced \\
\hline $\begin{array}{l}\text { Motivational } \\
\text { force }\end{array}$ & Strong & Strong & Overtly & Not overtly \\
\hline
\end{tabular}

\begin{tabular}{|l|l|l|l|l|}
\hline & Mrs Winters & Mr Cole & Mr Garibaldi & Mrs Alexander \\
\hline Expectancy & $\begin{array}{l}\text { Somewhat } \\
\text { convinced }\end{array}$ & Convinced & Convinced & Convinced \\
\hline Instrumentality & Convinced & $\begin{array}{l}\text { Somewhat } \\
\text { convinced }\end{array}$ & Convinced & $\begin{array}{l}\text { Somewhat } \\
\text { convinced }\end{array}$ \\
\hline Valence & Overt & Not overt & Somewhat overt & Overt \\
\hline $\begin{array}{l}\text { Motivational } \\
\text { force }\end{array}$ & Average & Average & Strong & Strong \\
\hline
\end{tabular}

\begin{tabular}{|l|l|l|}
\hline & Mrs Ivanova & Mr Franklin \\
\hline Expectancy & Convinced & Convinced \\
\hline Instrumentality & $\begin{array}{l}\text { Somewhat } \\
\text { convinced }\end{array}$ & $\begin{array}{l}\text { Not applicable } \\
\text { (no program) }\end{array}$ \\
\hline Valence & Overt & Somewhat overt \\
\hline $\begin{array}{l}\text { Motivational } \\
\text { force }\end{array}$ & Strong & Not applicable \\
\hline
\end{tabular}

\subsection{The corporate HR perspective}

With the participants' perception of the different developmental programs presented, it becomes relevant to state the view of the HR-department on these programs. The main information in this section comes from Mr Kelso as head HR officer, Mr Sullivan as head of Talent Management, Mrs Reed as Head of HR in one of Circfor's business areas, Mr Garibaldi as the manager in charge of developing and implementing these programs in practice, and secondary data regarding the developmental programs.

An overview of the information provided regarding the development programs reveal a certain degree of alignment between the content of the development programs and the suggestions made by Cacioppe's (1998) literature review, who states that business game simulations, personal development and business skills to be supremely important for developing global leaders, though an in-depth study of the programs is necessary to determine the degree of correspondence. 


\subsubsection{Development program attendees}

The developmental systems described in the Findings-section were available to different sections of the interviewees. Though the argument could be made that as many employees as possible should be allowed to attend these programs, this would likely entail financial costs, and might also be rather unadvisable. Gregerson et al (1998) suggest that only certain individuals should be nominated for developmental progress, preferably judged by their perceived ability to become global leaders in the future. As a matter of fact, one major finding of their paper research was that companies with organized systems of developing global leaders (presumably including assessments) performed financially superior to companies without such systems, suggesting that the exclusion of non-adept individuals from the programs to be beneficial. Caligiuri (2006) adopts a somewhat similar position, arguing that companies can develop individuals to attain adequate and relevant skills, or hire people from the outside who already possess such skills. The determination of who to develop is thus dependent on the available time and resources of the company in question.

The interest in self-development and many of the statements issued by the interviewees can be related to several nudges given by the higher HR- regarding the self-propelled development of one's career. Quoting Mr Sullivan, "Everyone is the smith of his own fortune”, meaning that although competence and inherent traits can be beneficial for any employee's own development and that their abilities are indeed measured, an important aspect in terms of development is the capacity to drive one's own development. Rather than waiting for the chance to be invited to a training program or a new position, Mr Sullivan stated it to be rather beneficial if the individual highlighted his or her capacity, will and interests, which can be brought up during the annual performance reviews. The idea of letting individuals themselves be responsible for their development mirror the ideas presented by Simmering et al (2003), who states that individuals may to some degree develop themselves.

Mr Kelso reinforced the importance of employee decision making, but was inclined to look at the members at different levels in different lights. While stating that level 4 managers had a propensity to request additional development programs, managers at level 2 and 3 were less prone to do so, believing their development to have come to an end and no longer requiring improvement. When looking at the intended levels of the Circfor developmental programs however, one can clearly observe that some programs - for instance the TED and the NODE - 
are aimed at managers more senior than level 4. The non-voluntary nature of these developmental programs may thus be explained.

Both Mr Sullivan and Mr Kelso agreed that managers and employees may disagree on the employee's development the nature of the situation all but unchangeable. The interests and perceptions of the two parts may never fully synchronize, though Mr Kelso mentioned that in an idealistically perfect world, the employee and the superior may agree on the developmental needs of the employee.

Furthermore, the international aspect of the development programs should be mentioned. In all of the development programs, the aims and purpose relate to the importance of international training, and also causes the makeup of the attendees to be international by inviting participants from different nationalities.

\subsubsection{The global aspect}

Mr Kelso mentioned that the creation of a global mindset was of major relevance for managers at a cross-national level. Indeed, with the international aspect of high-level management and global leaders being mentioned by Mr Kelso, Mr Sullivan and Mr Garibaldi (responsible for implementation of development programs) alike, the global nature of the program seems rather unsurprising. The degree to which the program is successful or not requires further interviews and would benefit from a long-term investigation, beyond the scope of this thesis. Its connection to theory is somewhat clearer, however. Emphasis on cross-national experience has been mentioned in theory (Gregerson 1998), yet these refer more to international experience in the form of long-term assignments and expatriation programs. The impact of training programs taking place in different geographical places and participants of different nationalities has not been as clearly emphasized. Thus, their relevance is not easily predicted.

\subsection{Individual perceptions and motivation}

Information extracted from the findings section reveals several motivational reasons for the employees. One of the most common issues considered was increased knowledge and development of the self in a professional or personal capacity, being mentioned by seven of the ten interviewees. Second, the possibility for social interaction was brought up by a total of six employees, thus meriting attention. Another commonly mentioned factor was the opportunity to engage in networking possibilities. Besides these three factors, the family issue 
was brought up as well, though rather as a factor affecting international relocation, thus indirectly affecting the interest in attending the development programs, or at least the development programs' effect on their career development. This borders the last relevant factor brought up - the effect that the development programs were perceived to have on the participants' careers.

\subsubsection{Increasing knowledge and self-development}

The most common reason to attend the development programs gaining increased knowledge, or developing themselves in their current work position. Indeed, all but three interviewees mentioned development, all but three mentioned increased knowledge, and only Mr Allan stated little expected benefits of attending the program. Since he felt already knowledgeable with one half of the program's contents and the other half was only semi-related to his field of work, that might be expected. However, this does not explain why individuals who have attended the same program several times - Mr Sheridan and Mr Cole for instance having attended the TED more than once - appear not to perceive the same lack of interest. Mr Cole did seem somewhat less enthusiastic than the rest however, having attended the TED numerous times. However, the focus of the TED does vary.

The expected development outcomes for the employees differ. Mr Sheridan expected improvement in his efficiency at work and in fields relevant for the future, while Mrs Winters mentioned to chance to develop himself "as a leader". Mr Garibaldi stated the program to be relevant "for my own development", and Mr Franklin expected development for himself and his leadership.

Since the purpose of the development programs are all stated to be related to increased knowledge and increased performance, the individuals' expectance that their knowledge should increase may not be puzzling.

\subsubsection{Networking opportunities and social interaction}

The possibility of increasing one's network was common as an expected outcome of attending developmental programs, especially by the individuals attending the GOLD and TED programs. Mr Sinclair saw it as a relevant goal of the development program, pointing out that without networking, one runs the risk of "reinventing the wheel", and that the possibility always remained high that someone had been in a similar position before. Hence, effective 
networking could prevent the need for individuals to invent solutions to already existing problems, saving work time and boosting efficiency.

Mr Bester mentioned that increased networking often leads to increased work efficiency (which, indicated by his stated intrinsic motivation, was one of his main motivational factor). He explained that if faced with a difficult problem, support or assistance from another employee having experienced similar problems could be provided if a network of individuals within similar traits already existed. Communication between such individuals could be significantly improved and more natural "... if one had shared a beer..." The value Mr Bester puts on the networking opportunity thus seems inherently tied to boosting the efficiency of his job position. It should be noted that he had mentioned social interaction and meeting new people as another reason for attending the seminar. Being head purchasing manager at Circfor and stating one of his more intrinsic job motivations to be developing himself and seeing other individuals develop, interest in expanding his network appears to fit with his motivation.

Further input on the topic was provided by Mr Cole, who early in the interview stated that social interaction, meeting people and allowing the company to cascade its view and philosophy to be of supreme importance. Perhaps strengthening his interest in the social dimension of the program is that fact that he considered knowledge development to be of little relevance, which in combination with his (ambiguous) confirmation of attending the program voluntarily suggests that social interaction was a reason for his attendance. That line of reasoning also connects to Mr Cole's statement that he enjoys working at Circfor because of the interaction with colleagues, the environment and the mood, his emphasis on social interaction appears understandable.

Regarding networking as a beneficial outcome of the development program, Mrs Alexander also put emphasis on the social aspect of the program. Though highlighting the international aspect of the program, her interest in the networking components did not seem extensive, and bring little additional information to the topic of networking. Her appointment to her current job is rather new however, leading one to assume that her interest in networking should be higher than presented in the interview. Relating to the social aspect of the program, these fit well with the intrinsic reasons mentioned in the interview, highlighting her need for a comfortable environment with her superior and colleagues alike. 
Mr Kelso mentioned in the informational interview that he had attended a number of selfdevelopment seminars one of the reasons being the opportunity to increase networking opportunities.

The importance of effective networking is highlighted in Bartlett \& Ghoshal (1992), who state that a global manager is not an individual, but rather a network of specialized individuals. Though not relating strictly to increased networking being essential for employee motivation, that factor has arguably already been addressed, both Mr Bester and Mr Sheridan stating efficiency increases as outcomes for increased networking, and both indicating such increases as part of their intrinsic job motivation.

\subsubsection{Family situation}

In total, seven participants in this study provided background related to their families, mentioning spouses and children, while three interviewees not mentioning the topic. Family situation is often brought up in global leader theory as a hindrance for global leader development by limiting their interest in moving abroad for extensive periods of time (see for instance Harzing \& Pinnington 2011, chapter 6). Indeed, five interviewees overtly stated that family had affected or is now affecting their willingness to move or accept assignments necessitating their moving. Only one of the interviewees stated having a family yet working in a situation which limited family interaction. The fact that family situations are common in preventing individuals from partaking in international assignments and travels is not new however, having been covered extensively in literature regarding both global leaders (Oddou et al 2000) and expatriate development (Harzing \& Pinnington 2011; Briscoe, Schuler \& Tarique 2012).

However, the impact on program development interest because of family seems somewhat limited however. Most likely, the fact that the development programs last a fairly short amount of time - the GOLD lasting roughly two weeks and the TED lasting 3-4 days represents little immediate impact on the interviewees' willingness to attend them. The NODE seminar lasts merely two days, thus also not severely impacting family life. Though some information was extracted with regards to international work and family, mentioned by six employees, those were not exclusive to development programs. Furthermore, these findings have already been covered in theory cited above, making these findings somewhat moot. 


\subsubsection{Career influence}

The rather contextual factor of what influence the development programs could have on future careers was also investigated. Curiously, few participants expected their participation in the development program to have a direct effect on their future careers. Mr Bester had a rather clear perception of his next career steps, and overtly mentioned that for either of the two possible career moves, formal education could not provide necessary preparation, but rather that experience in the field was the missing component. He also perceived the advancement of his career to include a widening of his authority and area of responsibility. When asked if a certain developmental program was necessary, he stated that the procedure might work the other way around - first being assigned to an area, then partaking in developmental programs for that specific area.

Mr Sheridan presented an opinion rather similar to his peers; not expecting his future career prospects to be positively affected by the development programs. As with the other interviewees, he noted that experience is the one deciding factor for his advancement. Similarly, Mrs Winters was quite aware where her career might progress and stated that though some education in areas such as press communication might be necessary, most information needed could be gained by experience, not mentioning developmental programs. Mr Cole for his part mentioned several positions to which he could be promoted, yet noted that development programs could do little to prepare him any of those positions. Furthermore, he did not expect Circfor to provide a preparatory program.

Mr Garibaldi noted that attending a certain psychology education would be directly beneficial in his job situation, yet said little about his chance of advancing career-wise or what effect that particular development seminar would have on his future career prospects. His statements revealed that though he knew where a promotion could lead him, a lack of operational experience was the impeding factor rather than a certain developmental program. Mrs Alexander revealed that her likely career advancement opportunity required additional information regarding work routines, rather than a specific program education, meaning more experience instead of formal education.

Mrs Ivanova noted even stronger than her peers that her career prospects were unclear, and the development programs were not mentioned. One of her possible advancement opportunities required no further training or education, whereas her other obvious promotion 
required experience training. Last, Mr Franklin was in a rather similar situation, stating he needed experience in the field of personnel management rather than additional development programs. Overall, it appears clear that few interviewees believed their participation in a developmental program to be related directly to career advancement. Whether this is the case or not is difficult to determine, yet the perceptions of the attendees are not. It should be noted that the purpose of the development programs are not overtly stated to be beneficial for employees' career advancements. Combined with the fact that several interviewees mention the need to be active in their own development, their perception that career advancement is based on performance rather than participation and the fact that those views are supported by the HR staff, this should perhaps not come as a surprise. Nevertheless, the impact on this case seems negligible.

\subsubsection{Individuals' knowledge of the programs' information}

At this point, the way information is disseminated to the future participants becomes relevant. Relating again to the expectancy theory, the expectancy of an individual to be able to complete the development program is affected by the individuals' perception of the program's difficulty. In a similar vein, information about the programs can influence participants' instrumentality and help them determine if succeeding the program will indeed lead to their expected outcome.

As stated above, performance evaluations are held on an annual basis to provide an overview on the performance of the relevant individual. Based on a number of criteria not necessarily relevant to this thesis, the employees can be nominated by their superiors for attending developmental programs. Mr Cole, for example, was nominated for attending the GOLD program, but prevented from attending due to scheduling difficulties. Though this would be her first developmental program within Circfor (implying no information on other programs), she had a strong desire to attend, mentioning that she had been given information about the content, length and whereabouts of the program, yet still perceived somewhat of a lack of information. Her positive attitude towards the company, revealed when asked about satisfaction in her current position, may imply a belief that the program would live up to her expectations.

One aspect stands out, however. Given the fact that the employees are nominated for attending the development programs during annual performance appraisals and the fact that 
Mr Cole mentioned that information regarding the program was given to her during that feedback session - why did she still perceive a lack of information? This implies either that the information provided to her during that feedback session was insufficient, or that information of the GOLD was overall unavailable to her, or that information was available to her, yet she chose not to seek it up. This matter is further problematized due to the fact that both Mrs Winters and Mr Franklin stated they knew of no relevant development programs for them - even though Mrs Winters has been working at Circfor for a year and a half, and her level qualifies her for the TED program. Though it is possible that her performance negates her inclusion, her lack of knowledge of the program does seem peculiar.

\subsubsection{The international aspect}

The wish for international contacts and exposure was somewhat unevenly distributed across the interviewees. While Mrs Winters, Mr Garibaldi and Mrs Ivanova were openly positive to having international contacts, responsibilities and travel, Mr Allan, Mr Cole, Mrs Alexander and Mr Franklin were for different reasons less excited about the international aspects of their work. Mr Sinclair, Mr Bester and Mr Sheridan mentioned the possibility of international exposure, no one of them openly stated it was a driving force for them. The fact that senior executives perceived to occupy the position of global leaders did not state an interest in international factors is rather noteworthy. According to both their own and informational interviews, these three level 2 managers handle global issues on a constant basis and voluntarily attend development programs. Hence the fact that this is not being overtly mentioned by these managers is puzzling.

The perhaps obvious problem with a limited interest in travel and expatriation programs is the lack of experience and information that can come with such a mindset. While it could be argued that the higher managers possess extensive information, lower-down managers can ill afford to stay away from international experience. Oddou et al (2000) mention that though international travel is likely to be the best training tool available to training global leaders, it is not uncommon for individuals to have a certain unwillingness to take part in them. Interest in and understanding of intercultural issues and experience in global affairs is not an uncommon idea. For instance, Gregerson et al (1998) point to the fact that successful global leaders are invigorated by travel, working in different languages and are invigorated by the differences around them. 
The fact that international travel was mentioned in merely four of the ten individuals in global leader positions is an anomaly. It relates poorly to statements in theory that interest and inquisitiveness is necessary for successful global leadership development. It should be noted that the possibility does remain that the interviews did not reveal sufficient information from the interviewees to confirm their lack of interest.

\subsection{Anomalies and considerations}

To ascertain the relevance of the interviews conducted, this section will relate to the definition of the term "global leader" provided both by theory and by Circfor itself and relate those two to the attendees of these interviews. Though stated above that the term global leader is not specifically used within Circfor, it was mentioned on several occasions that a large part or a majority of the managers at Circfor face international challenges and are required to solve issues on a global level. As such, any head of business area would by definition be a global leader (thus referring to Mrs Reed, Mr Bester and Mr Sheridan), and that individuals at level 5 in the company more likely would correspond to a local or regional leader, thus hardly a global one.

When asked about conducted international expatriation programs, none of the interviewees had participated in any (lengthy) programs. With a few exceptions however (notably Mrs Alexander) the other interviewees had had international experience of varying degrees. For instance, Mrs Winters had been working for different American and Dutch companies abroad, Mr Bester has worked in London and Moscow, and so on.

Perhaps one of the most relevant findings from the conducted interview came from the informational ones in the beginning of the project. The tasks of the interview people at this company involve handling of different business areas or special topics and assignments within the Circfor structure, and indeed several of the employees have occupied their current position for a rather short time, even though having worked for Circfor a long time. While Mrs Ivanova and Mr Franklin have all been at the company for less than a year, both Mr Bester and Mr Sheridan have been working in Circfor for over ten years, though in their current positions circa two years. Several definitions of the term "global leader" refers to individuals managing subsidiaries and plants for a few years in different parts of the world, yet refers little to whether the individuals brought up in this case would qualify for this definition. Indeed, as established, several of the interviewees have had significant international 
experience, yet are not located at the Circfor headquarters, thus managing business areas of a transnational nature from the top, not steering the development of a single plant. This begs the question whether the definition of a global leader is dependent on the individual in question being assigned to manage a specific site or on the skills and experience obtained by that individual. Given the fact that much research papers (Harzing \& Pinnington 2011; Briscoe, Schuler \& Tarique 2012) have recommended reincorporation of individuals (global leaders and expatriates alike) with international knowledge into the company headquarters in order to retain and obtain their acquired knowledge, the assumption that the definition of a global leader should be dependent on them currently being assigned to an off-HQ site seems somewhat unrealistic. It could be argued however, that global leaders do indeed need to occupy a job with a certain degree of international exposure, lest he or she will lose the benefits of international experience over time, putting the experience side of the global leader definition debate on a continuum. This argument necessitates a discussion regarding the knowledge required for a global leader to possess and transmit, steering the issue in the direction of knowledge management, outside the focus of this thesis.

Relating to the definition of global leaders, Caligiuri (2004) (cited in Caligiuri 2006) lists ten tasks or activities being very common and also exclusive to global leaders, perhaps the most relevant ones being supervising employees of different nationalities, developing strategic business plans on a worldwide basis, managing foreign suppliers and vendors. Gregerson (1998) however, contesting that global leaders need a certain set of personality traits, relates his definition of global leaders to possessing a number of personality-related factors, which this thesis has little chance of relating to due to the fact that no personality questionnaire was issued to the interviewees. A third definition, mentioned in the beginning of the thesis, is the one provided by Caligiuri \& Tarique (2009), stating that global leaders are "high level professionals such as executives, vice presidents, directors, and managers who are in jobs with some global leadership activities such as global integration responsibilities." Utilizing this definition, every interviewee is likely to fit in, though a gap in the definition becomes rather apparent: there is a lack of categorization of "high level managers", and the degree of influence that would-be global leaders must have on global leadership issues. 


\section{Conclusions}

\subsection{General conclusions}

\section{Global leadership development tools}

17 development programs are available for the employees' benefit, though limited to them based on their managerial level. Of the five interviewed individuals, four became relevant. Attending these programs is contingent on being nominated in annual performance measuring discussions, though the possibility exists for potential attendees to highlight their own interest in attending the programs. The head of the group HR department reported that though the training programs were the mainstay of the development programs, individual coaching and on-the-job training is available as well. The fact that a number of different development methods and programs were available is likely to be dependent on the fact that individuals need to be educated based on different circumstances and contingencies. As the head of the HR department stated when asked how to educate global leaders: "That's a good question".

Though in the case of Circfor there were technically seventeen development programs available for its employees, this thesis has three of them in focus. The TED program is available for the top echelons of Circfor, accepting employees of level 4 or above, letting them partake in a business simulation aimed at increasing growth and performance. The flagship program is the GOLD, aimed at level 4-6 managers, whose contents of strategy, finance, leadership and people management aims to provide tools for further development. The NODE seminar introduces new managers into the Circfor culture and provides them with more information about the company. Revealed in the interviews was also that some external training was possible, though again being granted those educations was contingent on an agreement with one's supervisor.

There are generally many more employees interested in attending the programs than there were slots open. Though lack of resources were likely a reason for not including every applicant, there is also theoretical support for doing so, arguing (perhaps crassly) that some individuals are more beneficial to develop than others. The fact that so many employees sign up for the program brings into light the individuals' perceptions of the development programs. When looking at the results from the analysis, it can be concluded that the majority of 
individuals did not perceive completing the programs successfully as an issue, and most also expected the programs to give them the outcomes they were expecting, which will be covered in the next section.

\section{Global leader development motivations}

Judging from the analysis of the conducted interviews, the reasons motivating global leaders to participate in development programs are related to either increased networking opportunities, chances to develop themselves in terms of skills or efficiency in their work, getting increased knowledge, or increased social experiences. These results resonate well with the findings of Jokinen's (2005) literature review, who found that common characteristics for global leaders include "social skills, networking skills and knowledge". To some degree it appears that previous knowledge of the available development programs can foster a willingness to participate.

Somewhat curiously, merely four of the ten confirmed global leaders stated an interest in increased international experience and exposure as reasons for attending the program, even though the description for each program includes international aspects and is made up of employees from different countries. This stands out against the majority of theory on the subject, which suggests that an interest in having tasks international aspects is essential for global leader development. It should be noted that the second of these two criteria was met, and that the possibility exists that the first was not definitively confirmed.

Perhaps related to the partial absence of interest in international aspects is the family issues, which appear to hold little sway over individuals' interest in partaking in development programs. It seems likely that if the interviewees did not perceive the chances of development programs leading them to a position requiring them to move abroad, this would bear little impact on their will to participate. Indeed, none of the interviewees expected the development program to be directly related to their career advancement. Rather, they noted additional experience in varying fields to be the lacking component in their training. This suggests that though development may well be beneficial to their efficiency, experience and on-the-jobtraining (mentioned by the head of the HR department) may be more significant. In a similar vein, some four employees showed little interest in further development programs; some perceiving no relevant ones to be available, others showing disinterest likely because of small expected gains. Furthermore, it appears that individuals were more inclined to attend 
development programs if they perceived the outcomes to be connected to their overall motivation, that they could complete the program successfully and when they believed that the outcomes would indeed be made manifest. This evidence is in line with the expectancy theory framework used and presented in the theory section.

\subsection{Research contributions}

The contributions for research in the field of global leadership development are twofold. First and foremost, anecdotal evidence from a number of global leaders has been presented regarding what motivates global leaders to partake in further development programs. Though a large degree of research has investigated how to develop global leaders, how to define the term and what traits global leaders should optimally possess, little research has been conducted in the field of what motivates their further interest in development. Interestingly, the results found in this study correlate well with the findings by Jokinen (2005) regarding important skills required by global leaders, as stated above.

Second, through informational interviews with members of Circfor's HR department, the definition of the term "global leader" has tested against the definition in practice. Relating the definition used in the beginning of the thesis "high level professionals such as executives, vice presidents, directors, and managers who are in jobs with some global leadership activities such as global integration responsibilities" to the one presented in the company as roughly being "the high level managers of Circfor", the correspondence between the two seems adequate. Given the fact that the managers referred to are the ones in level 1 through 4 , and the fact that all the interviewees at these levels are given international issues to address due to Circfor's inherent global nature, the relation between theory and practice seems present.

\subsection{Suggestions for future research}

The findings in this thesis culminate in two kinds of suggestions for further research. The first relates to propositions from the case study which may be used to further find a theory regarding global leader development. The second type is general suggestions for progress in the field, less related to the propositions found in this thesis.

\subsubsection{Propositions from thesis}

Based on the findings of this case study, a number of propositions can be made. Since these propositions are one the basis on a single case company, they will benefit from being 
replicated on other cases. Nevertheless, these findings were discovered via qualitative methods, hoping to reveal underlying mechanisms. These propositions embody these findings.

Proposition 1: Networking opportunities benefit global leaders' efficiency at work.

Several interviewees explicitly stated efficiency boosts from increased networking opportunities. Furthermore, as a number of interviewees have revealed, there is an apparent interest among the participants to increase their networking opportunities during the course of these programs. As stated also, benefits such as efficiency and ease of work were suggested, providing an additional reason for focusing on this aspect. As suggested by Bartlett \& Ghoshal (1992), the networking aspect is central to global leadership. The degree to which networking opportunities within development programs benefit the attendees' work efficiency should be investigated however, either by way of asking interviewees for their interest, or individuals already having participated in the programs whether these programs gave networking benefits.

Proposition 2: Development programs benefit from offering networking opportunities

This proposition is somewhat in line with the findings by Bartlett \& Ghoshal (1992). Besides the fact that attendees mentioned networking opportunities as a major benefit of development programs, given Mr Sinclair's statement that the wheel tends to be reinvented without proper networking, and Mr Sheridan's mentioning that increased networking can facilitate effective operations, it could be argued that increasing networking opportunities should be in focus in these kinds of development programs. Though training programs in global companies including managers from around the global may seem to inherently further such communication, this should not be taken for granted. First and perhaps most obvious, the nature of individual development programs can never be assumed to include such aspects in advance, and may differ widely from case to case. Second, this issue should likely be given further attention so as to ascertain the actual level of networking taking place in the company. Though Mr Sullivan mentions that one task of the GOLD program is intentional networking among its participants, one of the most common reasons for failure in development programs is believing one's own company to be international. (Ready \& Conger 2007) 
Proposition 3: Global leaders do not participate based on assumptions of career advancement

None of the interviewees expected the programs to have a direct influence on their immediate advancement opportunities, mentioning increased experience in different areas to be of greater importance. Most of the interviewees perceived outcomes of the programs to be aligned with their overall intrinsic motivation, hence suggesting their fondness for their job to be more important than advancement. The idea is given further credence by the fact that one interviewee did not perceive the program's benefits to be in line with his intrinsic motivation and expressed interest in another position for which he stated to already be qualified.

Proposition 4: Development programs should speak to the individual's development

Based on the results gauged from the interviewees and analysed, the majority of employees expected individual development, expansion of personal knowledge and some kind of increased social interaction as outcomes of these programs. Perhaps obviously, if the goal is to motivate individuals to attend development programs, offering them outcomes desirable to them is wise. Designing programs including features relating to these four aspects is only prudent however, if the findings of this thesis can be replicated. To some degree, this thesis is thus in line with the findings of Cacioppe (1998), stating personal development and increased business and leadership skills (somewhat parallel to this thesis' suggestions of increased knowledge) to be important.

\subsubsection{General suggestions}

As with many other papers on the subject, further research aimed at attaining an optimal definition of the term "global leader" way be warranted. This thesis utilized the definition provided by Caligiuri \& Tarique (2009), and though referred to as "succinct" by Harzing \& Pinnington (2011), the word "succinct" is not a synonym for "perfect" or "omni-applicable". As the Anomalies-section of this thesis mentions, the level to which global managers belong is still rather unspecific, and the degree to which they all possess to fulfil the traits necessary to be defined as a global leader is ever uncertain.

On a related note, as many a definition on global leadership refer to the skills and traits necessary by global leaders, it might be beneficial to conduct a number of personality tests on a representative sample, if such a mythical unit would exist. This is based upon the fact that 
traits such as inquisitiveness has been highlighted as relevant for global leadership development, and that skills such as social skills and networking skills have been deemed relevant in the same regard. Though trait research has (allegedly) fallen into disrepute and such a research project would border or cross the border into the field of psychology, its merit appears non-minimalistic.

There has also been extensive research conducted on the development of individuals being sent on international assignment and how to properly prepare them for the task to come. However, the tasks of global leaders are different from a mere expatriation assignment, not only in relation to the tasks having to be carried out, but also mostly in terms of previous experience and the degree of responsibility on part of the global leader. As such, it is rather unclear whether the lessons learned from developing expatriates will apply to developing global leaders. Thus, determining what motivates global leaders to partake in further development programs and in assignments abroad seems a relevant endeavour.

Lastly, given the fact that the findings of this thesis were based on the results of interviews from a single company, it would be advisable to replicate its findings. Though this should preferably be done in a quantitative way, investigating individual motivations via quantitative methods may not be overly simplistic. Nevertheless, determining if there are indeed general reasons for global leaders' interest in development programs could be rather beneficial for companies seeking to recruit them. Based on the data revealed in the beginning of this thesis, that amount of companies may be staggering. 


\section{References}

Bartlett, C. A., \& Ghoshal, S. (1992). What is a global manager? Harvard Business School.

Cacioppe, R. (1998). An integrated model and approach for the design of effective leadership development programs. Leadership \& Organization Development Journal, 19(1), 44-53.

Caligiuri, P. (2004, August). Global leadership development through expatriate assignments and other international experiences. In Paper presented Symposium: Expatriate Management: New Directions and Pertinent Issues" at the Academy of Management, New Orleans.

Caligiuri, P. (2006). Developing global leaders. Human Resource Management Review, 16(2), 219-228.

Caligiuri, P., \& Tarique, I. (2009). Predicting effectiveness in global leadership activities. Journal of World Business, 44(3), 336-346.

Campbell, J. P., \& Pritchard, R. D. (1976). Motivation theory in industrial and organizational psychology . In M. D. Dunnette (Ed.), Handbook of industrial and organizational psychology (pp. pp. 63-130). Chicago: Rand McNally.

Collings, D. G., \& Mellahi, K. (2009). Strategic talent management: A review and research agenda. Human Resource Management Review, 19(4), 304-313.

Colquitt, J. A., LePine, J. A., \& Noe, R. A. (2000). Toward an integrative theory of training motivation: a meta-analytic path analysis of 20 years of research. Journal of applied psychology, 85(5), 678.

Kets de Vries, M. F., Vrignaud, P., \& Florent-Treacy, E. (2004). The global leadership life inventory: Development and psychometric properties of a 360-degree feedback instrument. The International Journal of Human Resource Management, 15(3), 475-492. 
Gregerson, H. B., Morrison, A. J., \& Black, J. S. (1998). Developing leaders for the global frontier. Sloan Management Review, 40(1), 21-32.

Gummesson, E. (2007). Case study research. In: Gustavsson, B. The principles of knowledge creation: Research methods in the social sciences. Cheltenham, UK: Edward Elgar Publishing. pp 87-113

Guthridge, M., \& Komm, A. B. (2008). Why multinationals struggle to manage talent. The McKinsey Quarterly, (4), 10-13.

Harzing, A. W., \& Pinnington, A. (Eds.). (2011). International human resource management. Sage.

Hakim, Catherine (2000). Research design. Successful designs for social and economic research. London: Routledge

Jokinen, T. (2005). Global leadership competencies: a review and discussion. Journal of European Industrial Training, 29(3), 199-216.

Leskiw, S. L., \& Singh, P. (2007). Leadership development: learning from best practices. Leadership \& Organization Development Journal, 28(5), 444-464.

McDonnell, A., Lamare, R., Gunnigle, P., \& Lavelle, J. (2010). Developing tomorrow's leaders-Evidence of global talent management in multinational enterprises. Journal of World Business, 45(2), 150-160.

Morrison, A. J. (2000). Developing a global leadership model. Human resource management, 39(2-3), 117-131.

Oddou, G., Mendenhall, M. E., \& Ritchie, J. B. (2000). Leveraging travel as a tool for global leadership development. Human Resource Management, 39(2-3), 159-172. 
Pless, N. M., Maak, T., \& Stahl, G. K. (2011). Developing responsible global leaders through international service-learning programs: The Ulysses experience. Academy of Management Learning \& Education, 10(2), 237-260.

Rabotin, M. (2008). Deconstructing the Successful Global Leader. T + D, 62(7), 54.

Ready, D. A., \& Conger, J. A. (2007). Make your company a talent factory. Harvard business review, 85(6), 68 .

Robbins, S. P., Judge, T. A., \& Campbell, T. T. (2010). Organizational behaviour. Essex: Pearson Education Limited

Schuler, R. S., Jackson, S. E., \& Tarique, I. (2011). Global talent management and global talent challenges: Strategic opportunities for IHRM. Journal of World Business, 46(4), 506516.

Simmering, M. J., Colquitt, J. A., Noe, R. A., \& Porter, C. O. (2003). Conscientiousness, autonomy fit, and development: a longitudinal study. Journal of Applied Psychology, 88(5), 954.

Suutari, V. (2002). Global leader development: An emerging research agenda. Career Development International, 7(4), 218-233.

Townsend, P., \& Cairns, L. (2003). Developing the global manager using a capability framework. Management Learning, 34(3), 313-327.

Yin, R.K. (2007). Fallstudier: design och genomförande. (1. ed.) Malmö: Liber 


\section{Appendix I - Interview guide, attendees}

A) Introduction, your background

$\square$ Role in company

$\square$ Time at Trelleborg

$\square$ Management level

$\square$ Info about international assignment(s)

$\square$ Info about development program(s)

$\square$ Main driving force (Valence)

B) Current position

$\square$ Satisfied / unsatisfied at current position

$\square$ Reason for un/satisfaction at position

$\square$ What do you like at position?

$\square$ What do you dislike at position?

$\square$ What could make you leave position?

$\square$ Perception of a clear career ladder?

$\square$ Can you climb it?

$\square$ Odds of you successfully completing that step? (Expectancy)

$\square$ Will this lead to advancement? (Instrumentality)

$\square$ Work load / job control

\section{C) Development programs / international assignment}

$\square$ Level of development program already attended

$\square$ Reason for attending (valence)

$\square$ Odds of fulfilling education successfully (expectancy)

$\square$ Belief that education (FLO) leads to reason for attending SLO (valence) (instrumentality)

$\square$ (Program not attended)

$\square$ (Reason for not attending)

$\square$ What program would you like to attend?

$\square$ Reason for attending (valence)

$\square$ Belief that education (FLO) leads to reason for attending SLO (valence) (instrumentality)

$\square$ Odds of fulfilling education successfully (expectancy)

$\square$ Will this lead to your overarching goal?

$\square$ (Info about advancement because of environment/language/other things) 
A) Open questions about the company's TM-settings

$\square$ Role in company

$\square$ Business unit structures

$\square$ HR structure

$\square$ Company Talent Management

$\square$ Use of global leaders

$\square$ Number developed per year

B) Global leadership in Circfor

$\square$ Definition of global leader / characteristics

$\square$ Global leader work tasks

$\square$ Key characteristics of global leaders

$\square$ Standardized criteria or situation dependent

C) Identifying global talents

$\square$ Criteria and practices for identifying global leaders

$\square$ Available development programs

$\square$ Biggest problem in global leader development

D) Learning processes vs talent management

$\square$ Individual responsibility for development

$\square$ Proceeding after identification

$\square$ Low global leader recognition from superiors

$\square$ Who determines HR development?

E) Future of the field

$\square$ Perceived future change

$\square$ Effect on company

$\square$ Plan to address future change

$\square$ Biggest challenge for future 